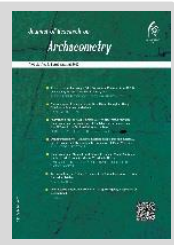

\title{
Characterization of Historic Mortar from the Architectural Decoration and Plaster of Rocky Temple of Verjuy in Maragheh, Iran
}

\author{
Mehdi Razani $^{* 1}$, Yaser Hamzavi ${ }^{1}$ \\ ${ }^{1}$ Assistant Professor, Faculty of Applied Arts, Tabriz Islamic Art University, Tabriz, IRAN
}

Received: 29/09/2018

Accepted: 21/12/2018

\begin{abstract}
Temple of Verjuy or Mehr Temple is one of the particular monuments in the type of regional architecture, in the slope of Sahand volcano; has been located in Verjuy village in the suburbs of the Maragheh city, East Azerbaijan province, Iran. The Verjuy researchers believe that this building belongs to the Mithraism religion which is an Iranian ancient religion (248 BCE-224 CE). But, new excavation around the temple demonstrated that this building is a part of underground rocky architecture with an unclear date and history. Underground Verjuy temple has seven spaces with a number of holes which are connected to each other. According to the literature, the temple was a worshiping place before Islam, but since then, the evidence show that it was used as a mosque. The architectural decorations of the temple have not been taken into consideration and in general, a lot of references, repeat the first information related to the history, usage and stone carving of this temple. As the specific architectural decorations of this monument have not yet been scientifically studied, the exploring variety of architectural decorations as well as the characterization of materials used for making the decorations of this building would be one of the main objectives of this research. Based on the results obtained, the main decorations of temple are including: carving of Islamic Arabesque and Quranic inscriptions as well as Moqarnas decoration inside the dome of the main space of the building. The results also showed the application of mortar on architectural decoration as a plaster inside the building and also on the surface of Moqarnas as a very thin layer in Islamic era. Moreover, the field work (redrawing the plan of temple and describe of architectural spaces as a documentation of architectural decorations with photography) and sampling of plaster along with $\mathrm{XRPD}, \mathrm{XRF}$ and thin section petrography analysis were done. The results of this research show that, except for stone decoration, there is another decoration with lime base mortar in cover of Muqarnas work and some other places of the building, that this new finding is reported for the first time. This finding showed the application of the building during different periods and it is possible to attribute the earliest works and shreds of evidence of the use of the original dome in its new use in the Islamic era, to the Ilkhanid period.
\end{abstract}

Keywords: Architectural Surface, Verjuy Temple, Rocky Architecture, Mortar, Petrography, XRF, XRD

\footnotetext{
*Corresponding author: m.razani@tabriziau.ac.ir
} 


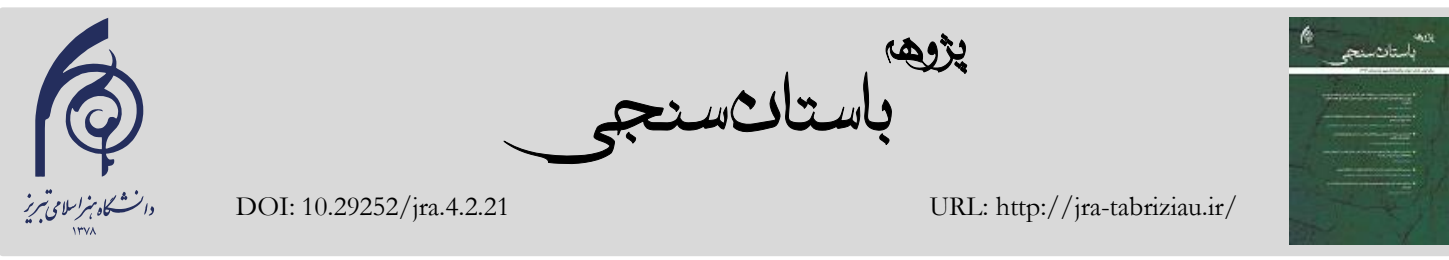

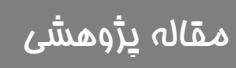

\section{ساختارشناسى ملاطهاى تاريخى در آرايههاى معمارى و اندود

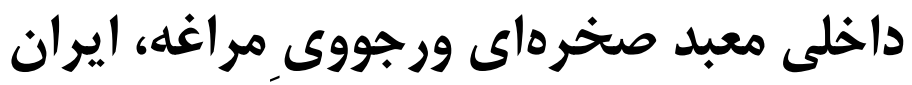

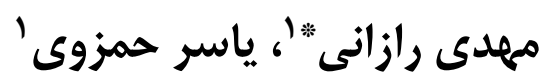

1. استاديار، عضو هيئت علمى دانشكده هنرهاى كاربردى، دانشگاه هنر اسلامى تبريز، تبريز، ايران

هدف اين يزوهش ارائه شواهدى جديد مبنى بر استفاده از ملاط در آرايههاى معمارى و اندودهاى بدنه داخلى معبد صخرهاى ورجـووى

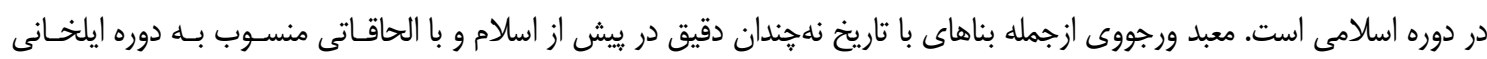

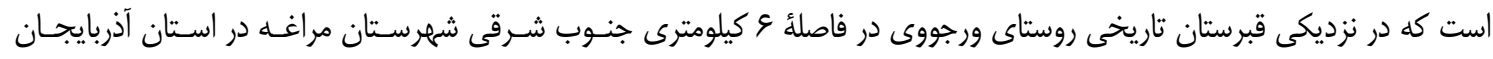

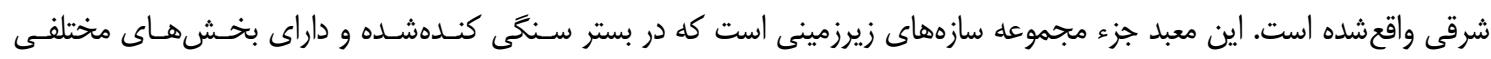

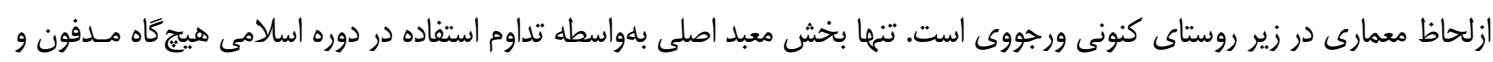

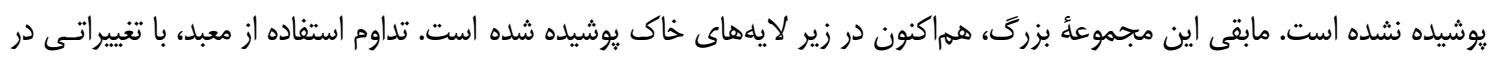

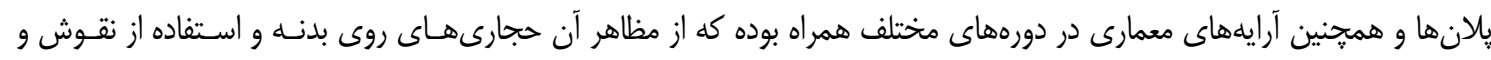

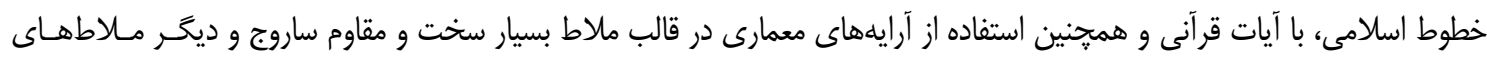

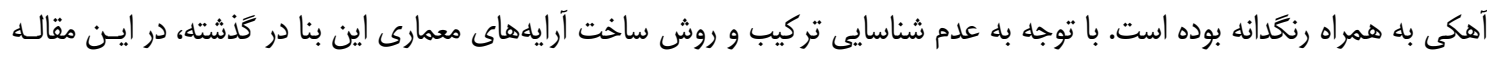

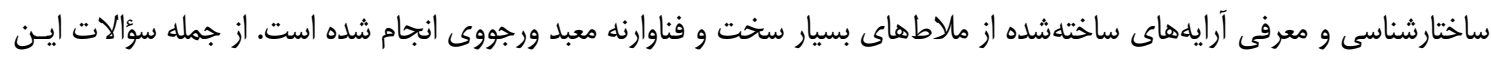

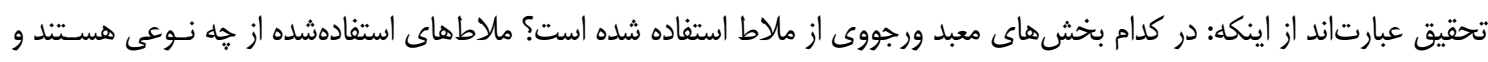

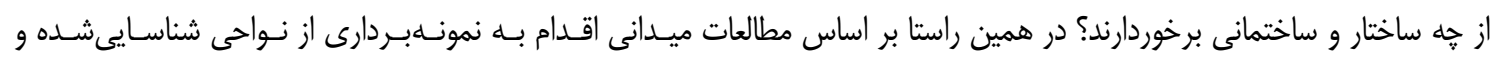

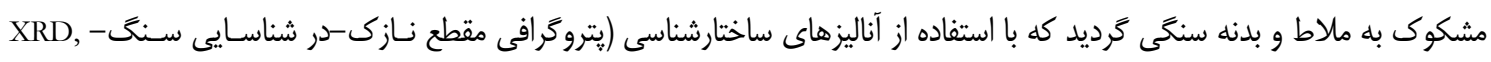

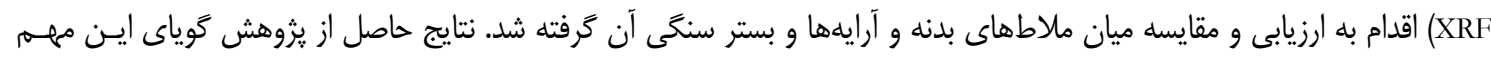

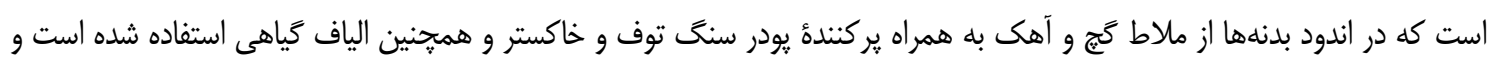
براى يوشش سطحى آرائة قطاربندى در فضاى V6، از ملاط ساروج مهره خورده استفاده شده است.

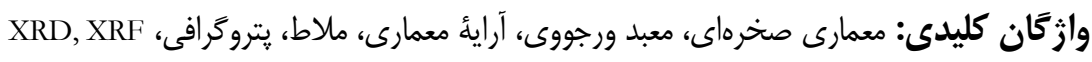

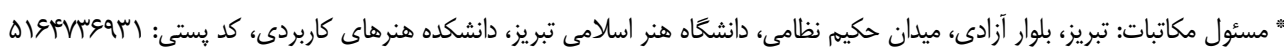

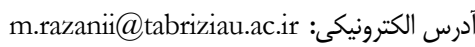

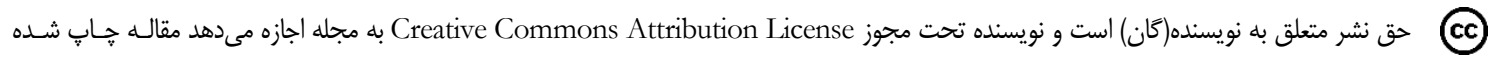
را با ديخران به اشتراك بكذارد منوط بر اينكه حقوق مؤلف اثر حفظ و به انتشار اوليه مقاله در اين مجله اشاره شود. 


\section{r. ييشينه تحقيق}

شهرستان مراغه با مساحتى حسدود

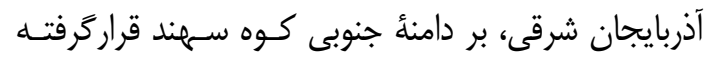

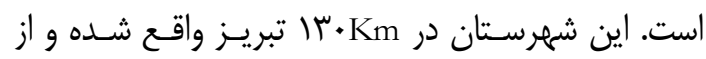

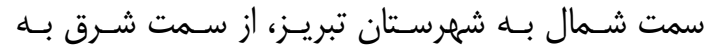

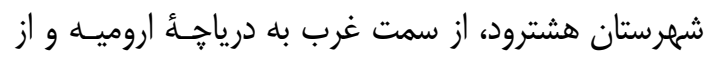

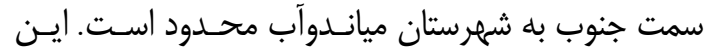

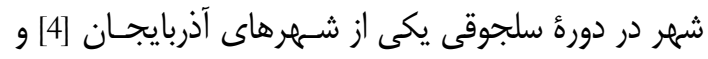

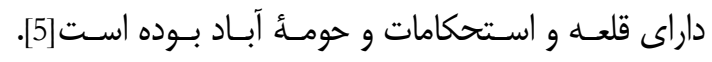

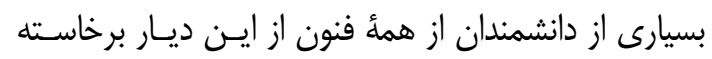

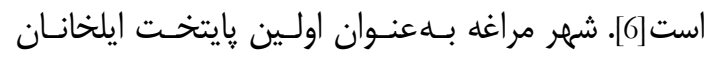

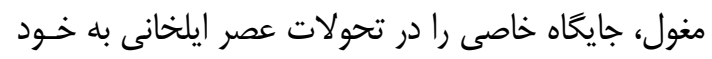

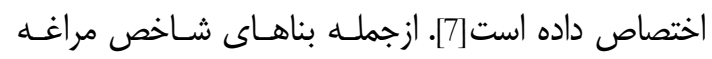

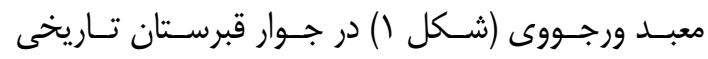

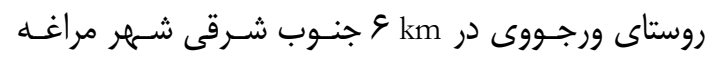

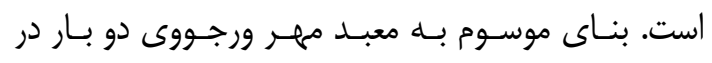

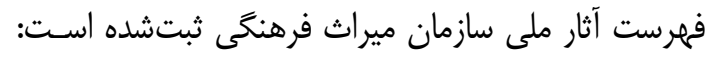

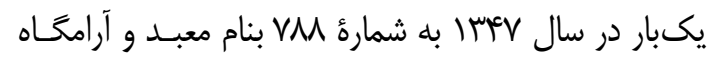

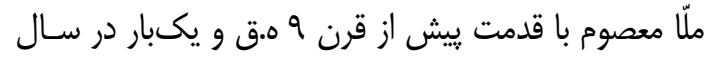

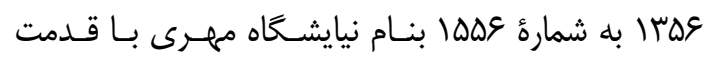

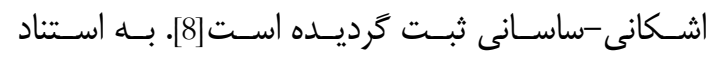

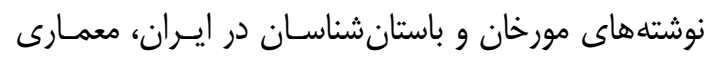
زيرزمينى مربوط به معابد دوره مهريرستى بوده است] [9]. و و

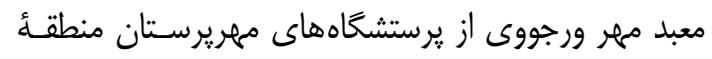

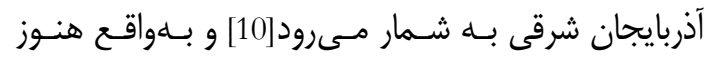

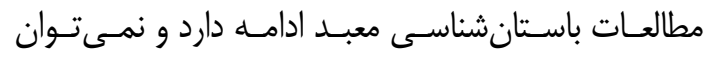

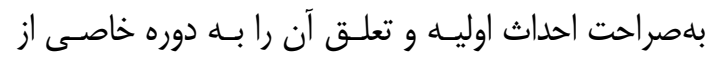
تاريخ يا مذهبى تاريخى بلصورت قطعى مشخص نمات المود.

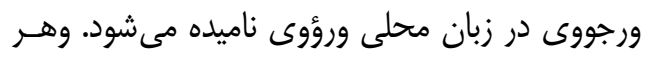

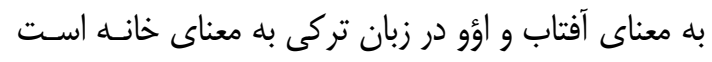

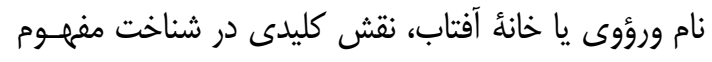

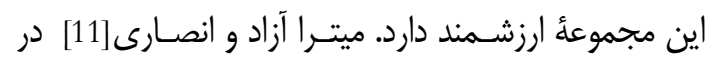

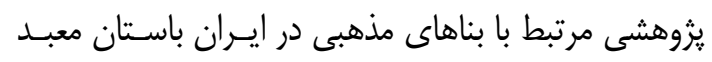

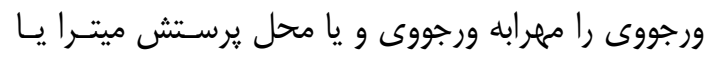

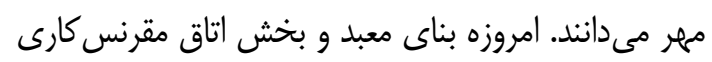

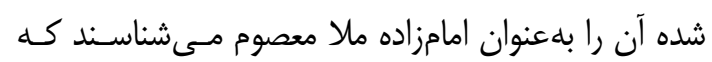

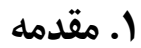

بيش از +.ب اثر ميـراث صـخرهاى در فهرسـت ميـراث

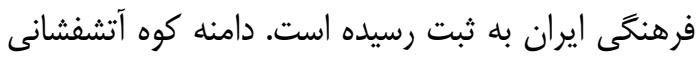

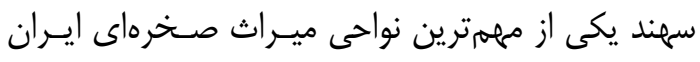

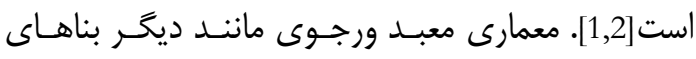

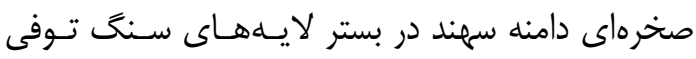

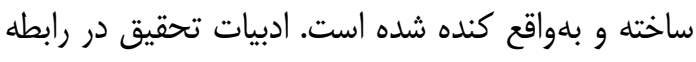

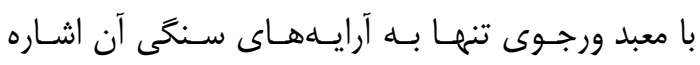

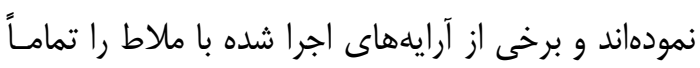

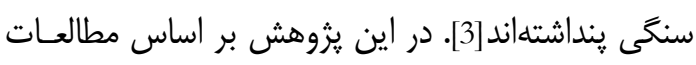

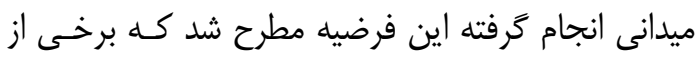

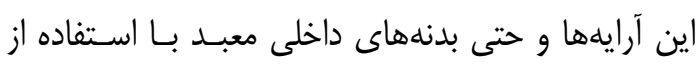

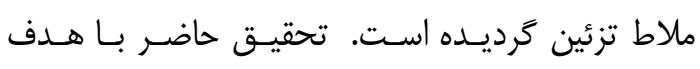

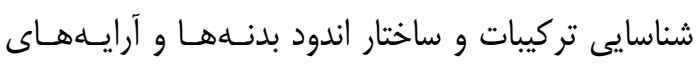

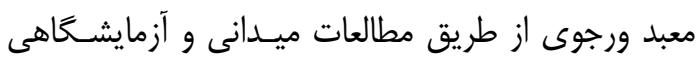

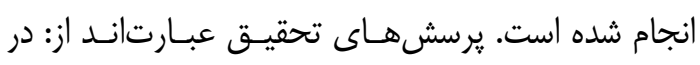

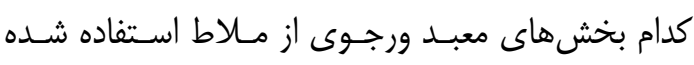

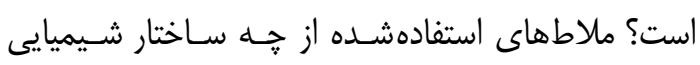

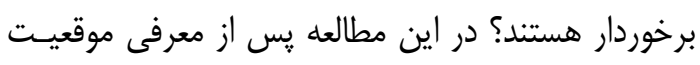

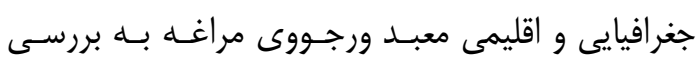

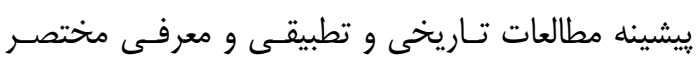

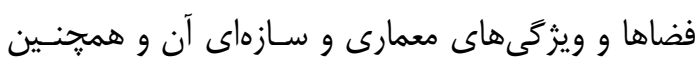

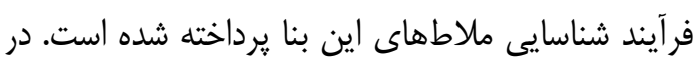

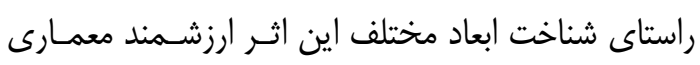

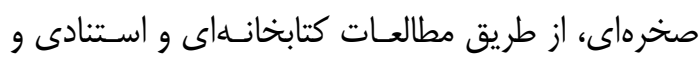

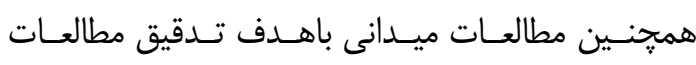

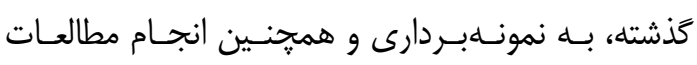

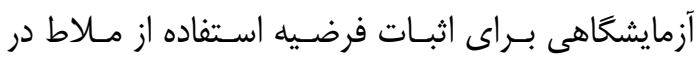

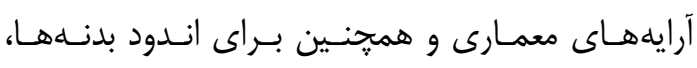

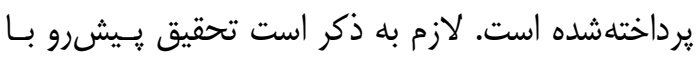

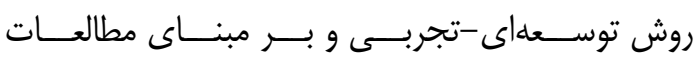

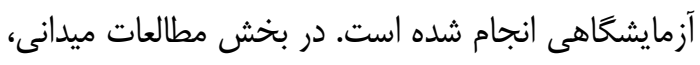

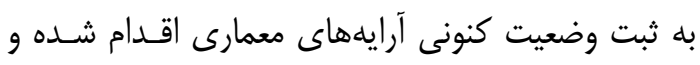

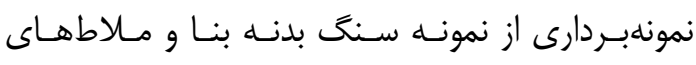

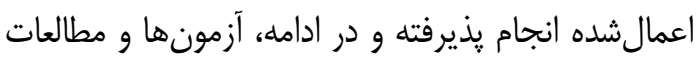
ساختارشناسى انجام و مورد تحليل قرار كرفته است. 
يزّوهه باستانسنجى

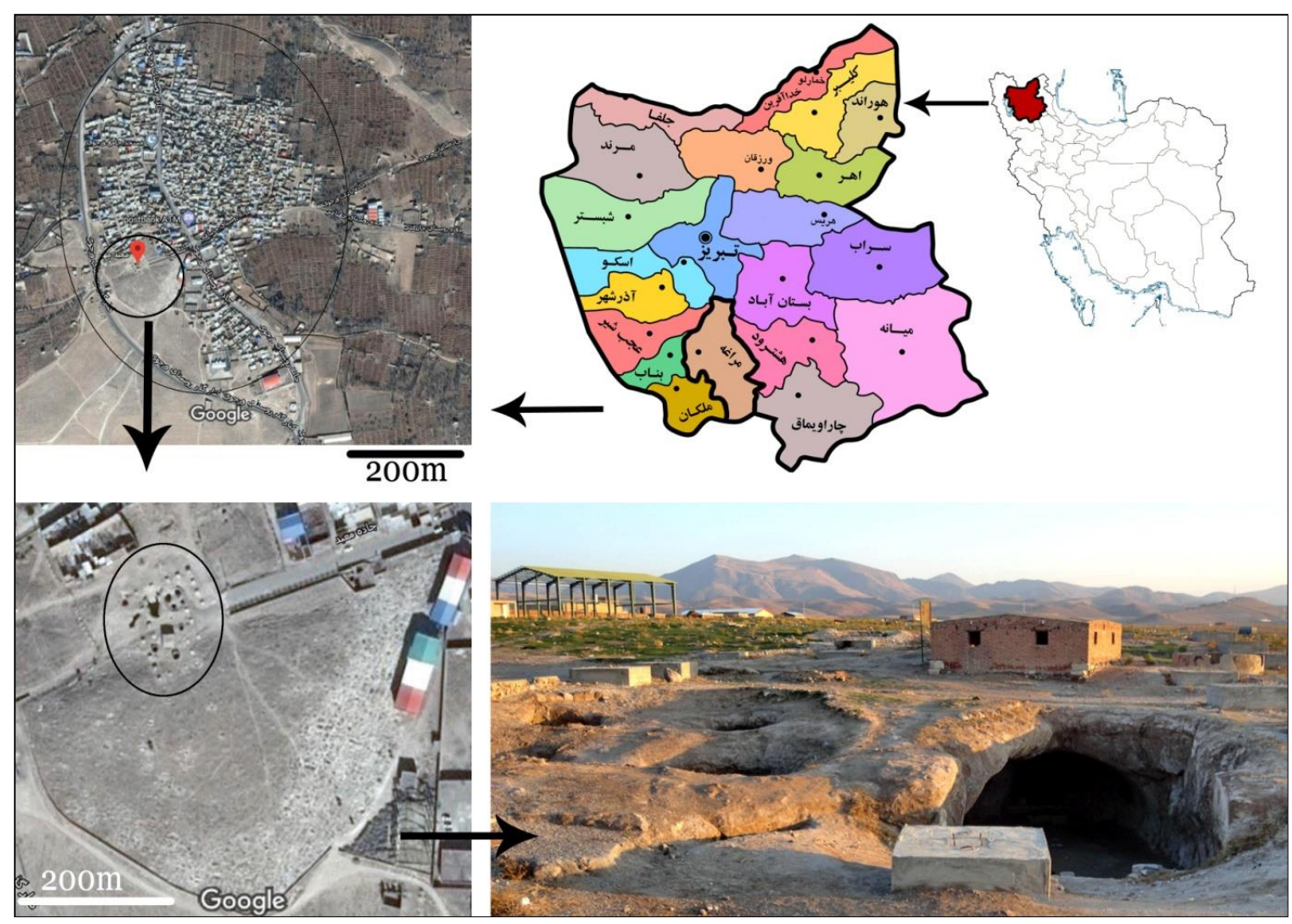

شكل (: موقعيت جغرافيايى شهر مراغه در ايران و معمارى صخرهاى معبد ورجووى

Fig. 1: the location of Maragheh city in Iran and Rocky Architecture of Verjuy Temple

حجارىشده آن با تاريخ بين قـرون ^ مـا Iل ه. ق. هنـوز

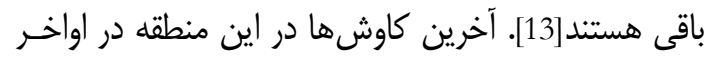

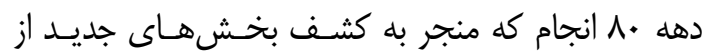

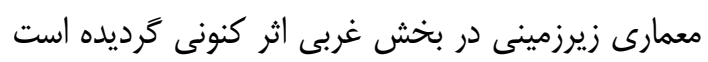

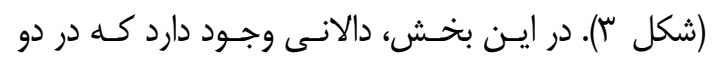

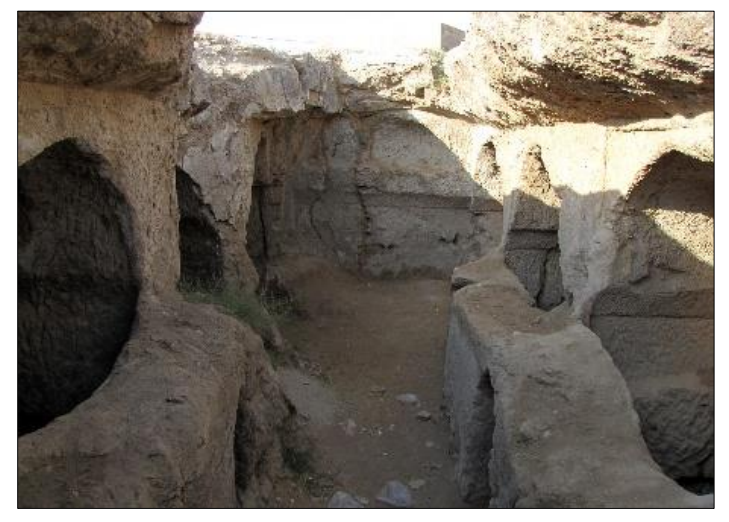

شكلّ: فضاهاى معمارى دست كند تازه كاوش شده در سمت غربى

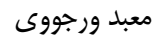

Fig. 3: The new rocky architecture spaces excavated near to the west side of Verjuy temple

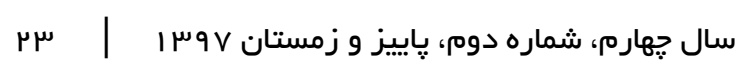

مدفن آخوند ملا معصوم مراغهاى (از علماى قـرن ساه.ق

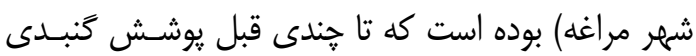

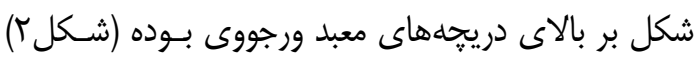

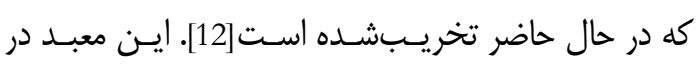

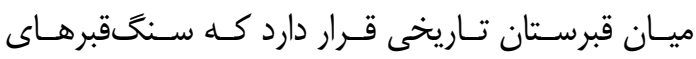

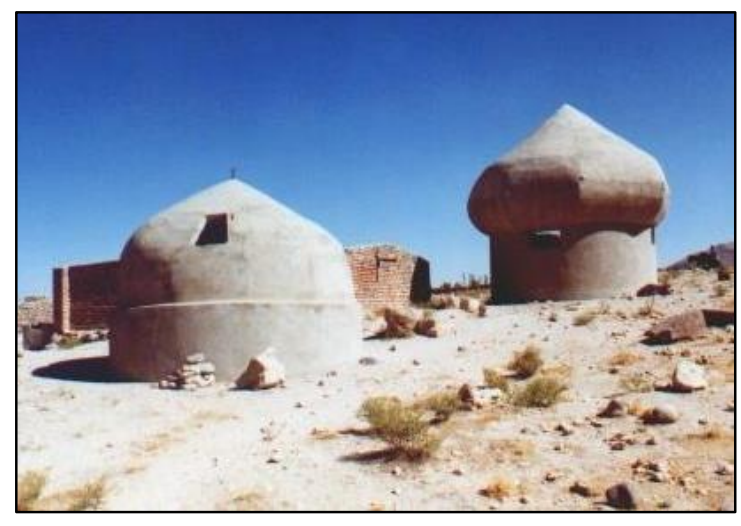

شكل ז: تصوير قديمى از دو كَنبد آجرى احداثشده بر معبد ورجوى

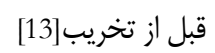

Fig. 2: The old picture from with two brick domes above the Verjuy temple before destroyed 
نقوش هندسى ساده و در قسـمت ميـانى، نقـوش گيـاهى انتزاعى (شبيه به اسليمى هاى سادهشده) ديـــه مسى شـود.

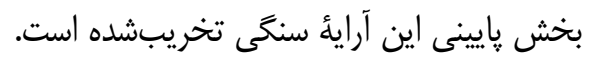

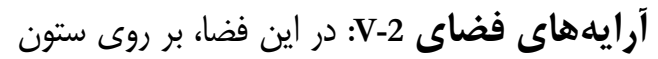

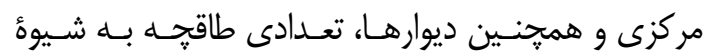

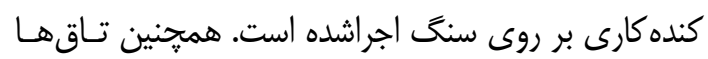
بلهورت كليل و يشتبغل بلهورت تخت و با زاويئة قائمه

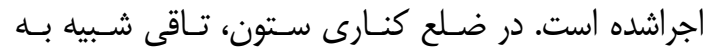

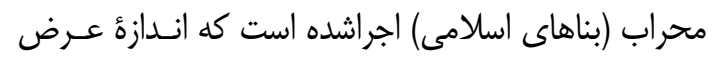

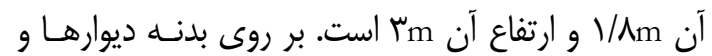

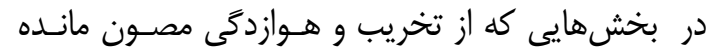

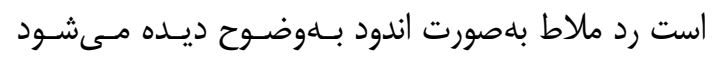

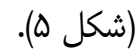

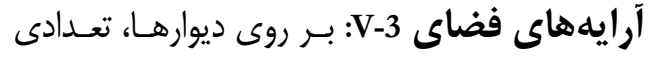

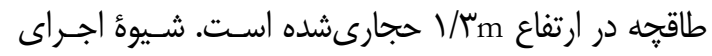

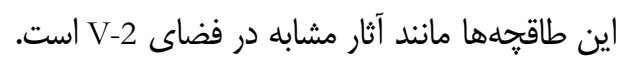

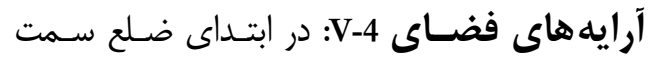

طرف آن غرفههايى با تاق و قوسهاى دوطبقه ديده

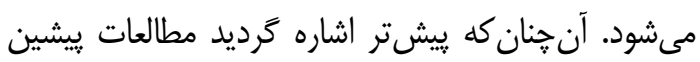
هيج كدام به وجود ملاط در بدنهان كائ معبد ورجوى مراغه اشاره نداشتهاند؛ ازاينرو مبحث ساختارشناسى ملاط آن نيز بههيجوجه موردمطالعه قرار نكرفته است و در اين تحقيق براى نخستين بار به آن برداخته شده است.

س. فضاها و آرايههاى معمارى معبد ورجووى

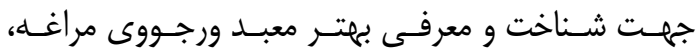

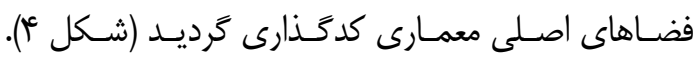

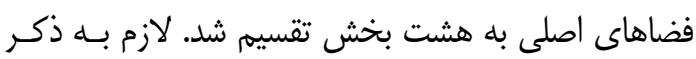

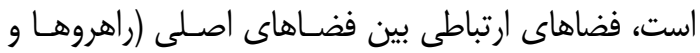
ورودى ها) كدگذارى نشده است.

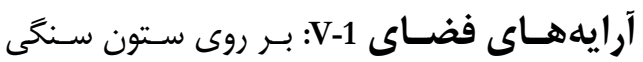

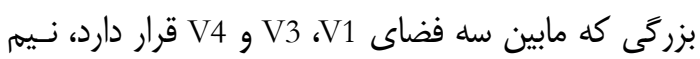

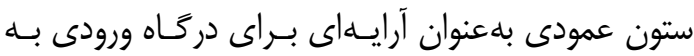
فضاى تالار اصلى حجـارىشــه اسـت. در قسـمت بــالا،

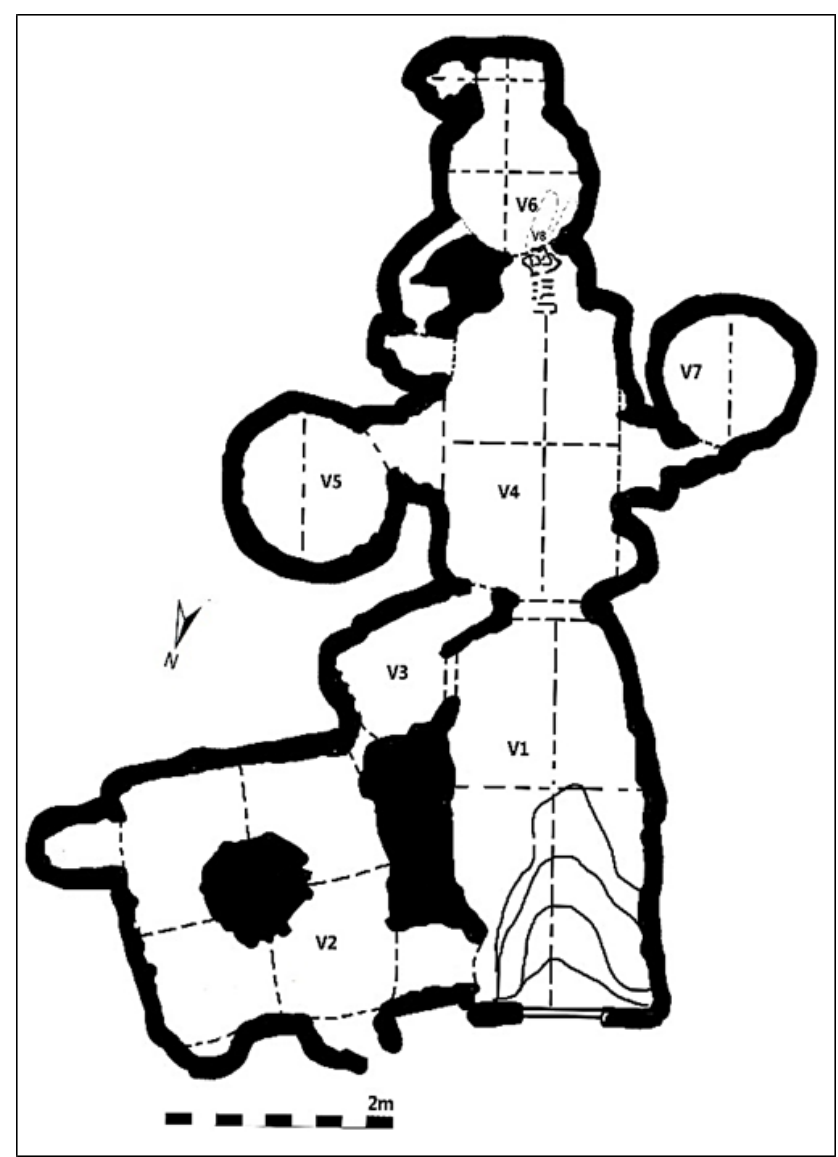

شكل ז: يلان معبد ورجووى و كدكذارى فضاهاى معمارى Fig. 4: The Verjuy Temple Plan and Coding of Architectural Spaces 


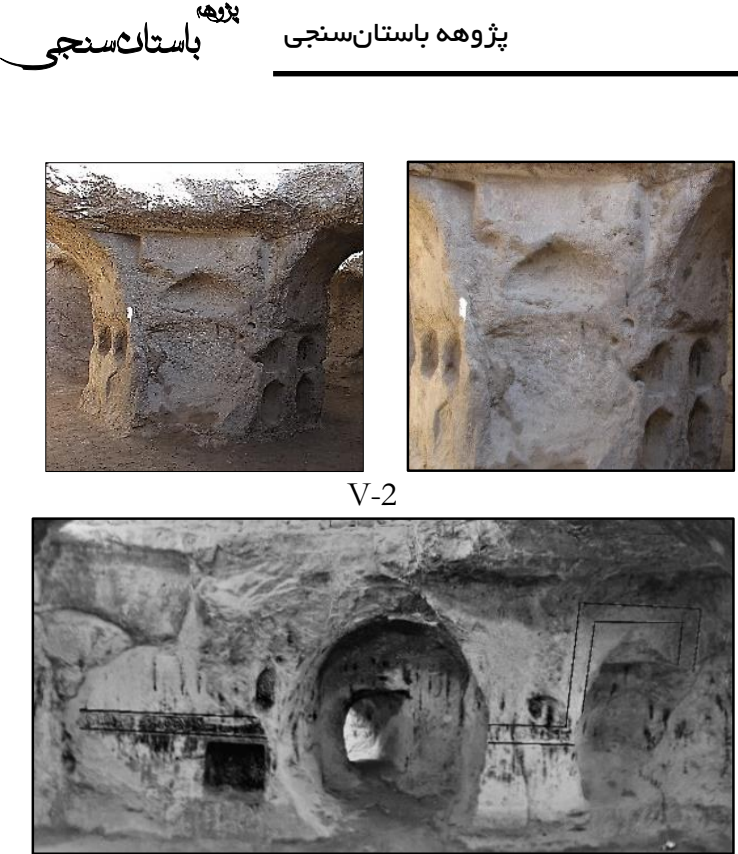

$\mathrm{V}-4$

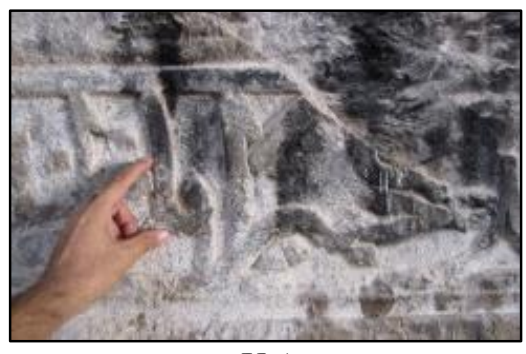

$\mathrm{V}-4$

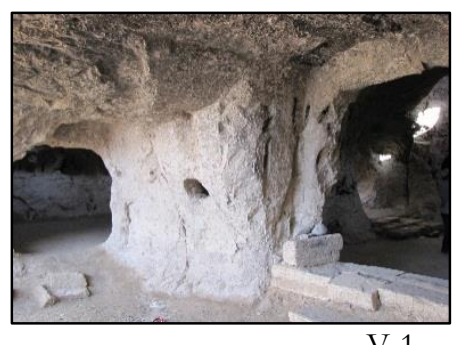

$\mathrm{V}-1$

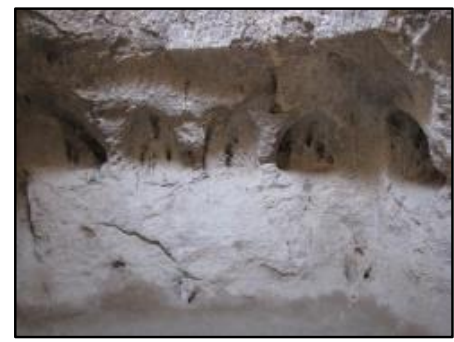

$\mathrm{V}-3$

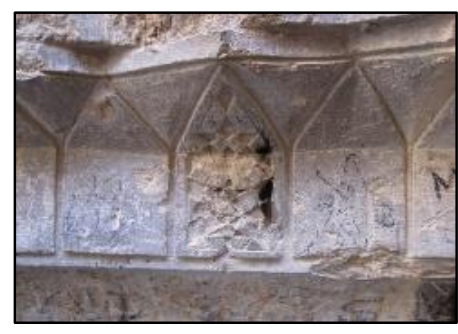

$\mathrm{V}-6$
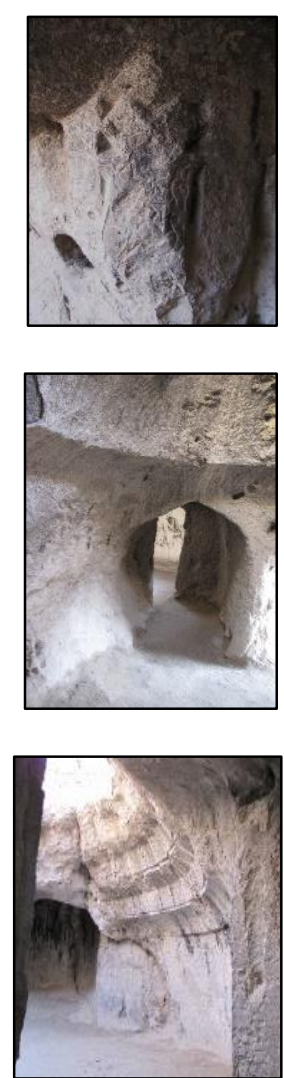

شكل ه: آرايلهاى معمارى معبد صخرهاى ورجووى بر اساس فضاهاى معمارى

Fig. 5: The architectural decorations in Verjuy temple based on architecture spaces
فضاى V-5 : فضايى با پالان شبيه به دايره است كه

با قطر m ه بلهصورت ساده و بدون تزيين اجرا شده اسـت.

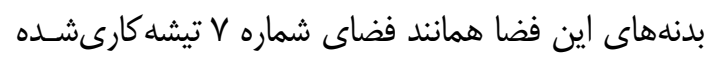
و آماده اندودكارى هستند.

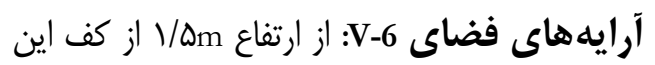

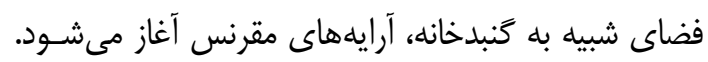

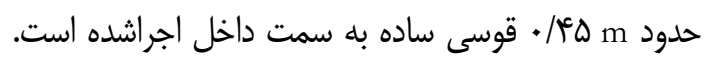

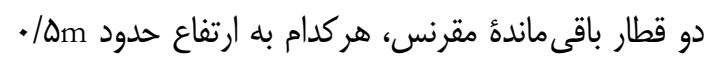

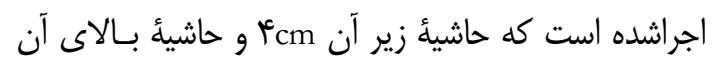

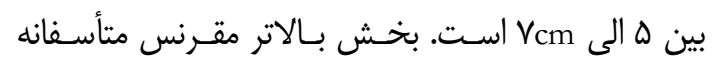

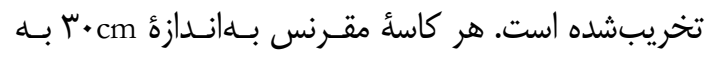

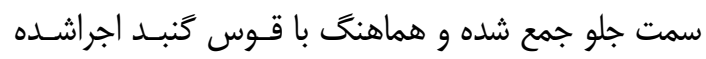
است. عمده ملاطهاى بله كاررفته، در اين فضا قرار كَرفتـه است. يكى از كاسههاى مقرنس در قطار اول، داراى نقش

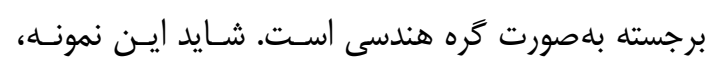
بلهورت الكَو براى ديخر كاسهها اجراشده كـه نيمـهــاره

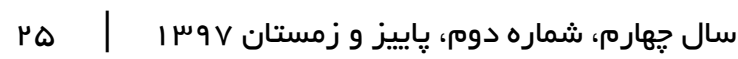

V- راست، بعد از وارد شدن به فضاى V-4 از سمت فضاى

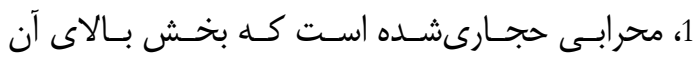

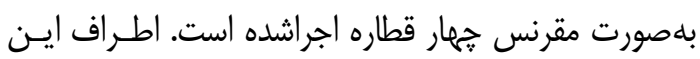

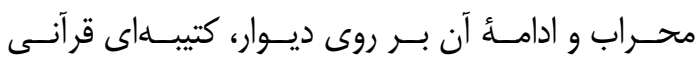

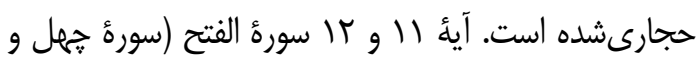
هشتم قرآن) در سه طرف مقرنس طاقنماى دست كند كه

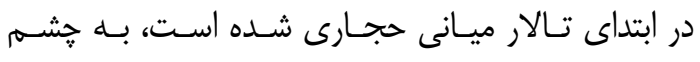
مى خورد كه بخشهاى زيادى از آن فرسايش ييدا كرده و

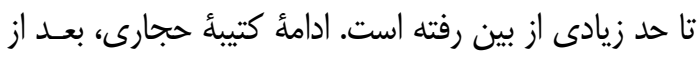

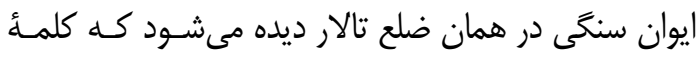

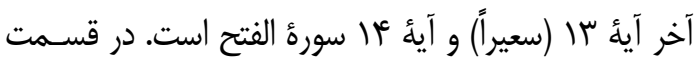

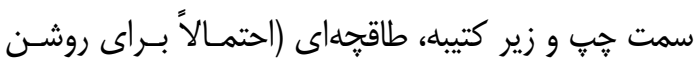

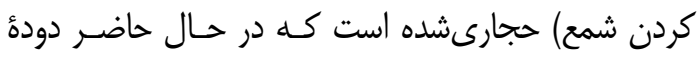

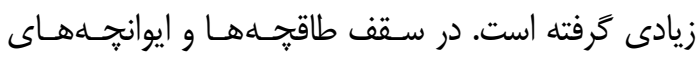

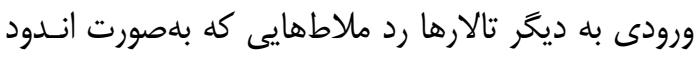
بر روى بدنهها اجرا شده است قابل مشاهده است. 


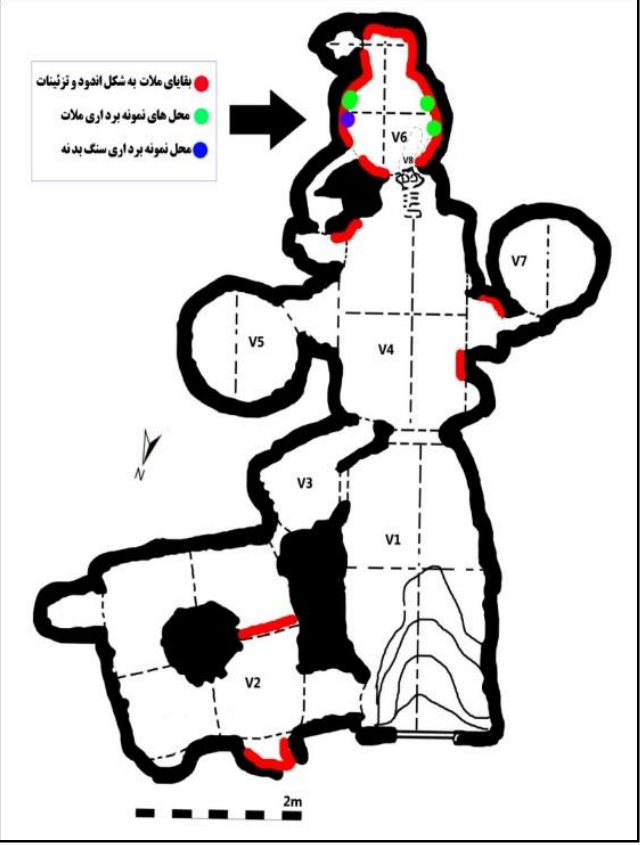

شكل \&: محل هاى نمونهبردارى در معبد ورجووى شامل: سنگ بدنه

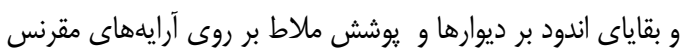
Fig. 6: Sampling points on the Verjuy Temple includes: Rocky substrate, remain mortars on the wall and covered mortar on the surface of Muqarnas decorations.

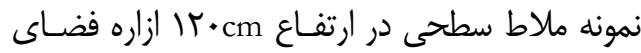

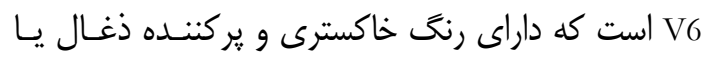
خاكستر است كه بلصورت انسدود بسـيار صـيقلى و مهره

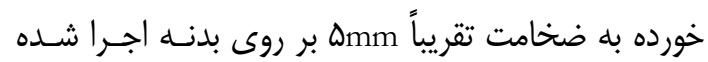

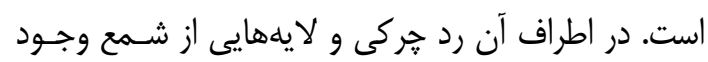

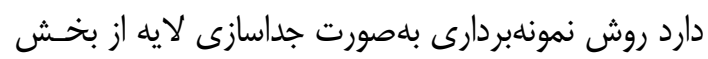

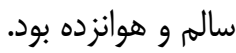
نمونه ملاط سطحى از آرايههاى مقرنس كارى فضاى ك6 كه داراى رنگ خاكسترى و ير كننده ذغال يا خاكسـتر

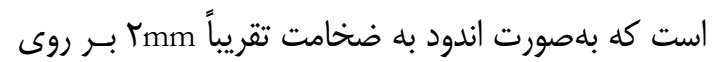

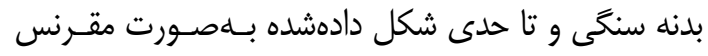
اجرا شده است. بر روى لايههاى ملاط ردى از فاز فشارهاى جندينباره بهوسيله ابزار بنايى وجود دارد.

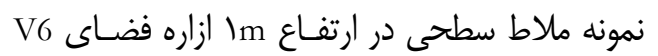
داراى رنغ خاكسترى و الياف گياهى همجيون لـوئى، كاه

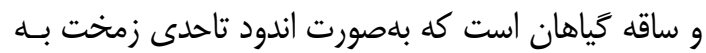

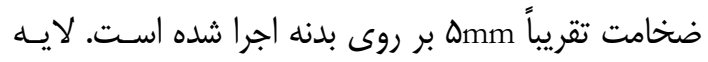

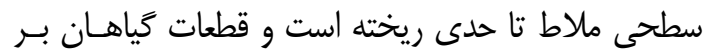

رهاشده است.

فضاى V-7: فضايى با يالان شبيه به دايره است كـه

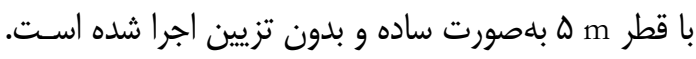

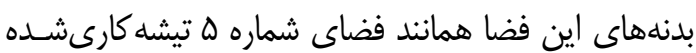

$$
\text { و آماده اندودكارى هستند. }
$$

فضاى V-8: بلهصورت ساده و بدون تزيين شامل دو هادئل

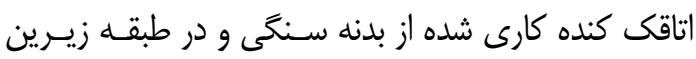

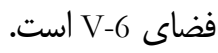

\section{F أ. مواد و روشها

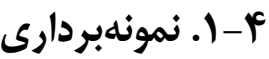

نمونهبردارى از بخشهاى اصلى مطالعـات ساختارشناسى

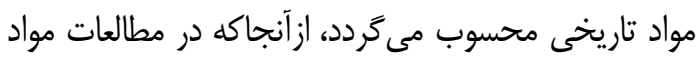

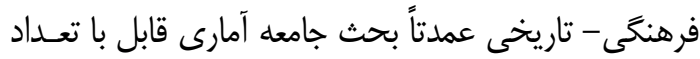

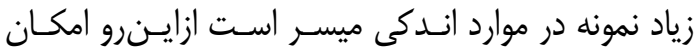

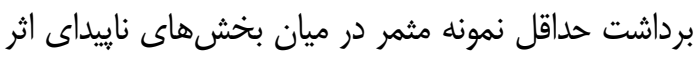

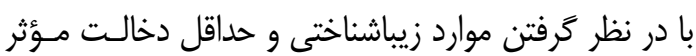

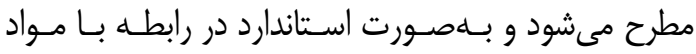

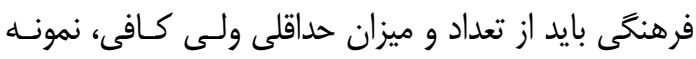

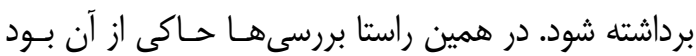

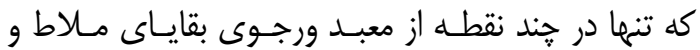

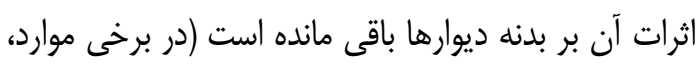

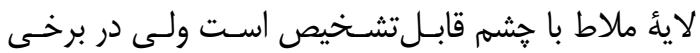

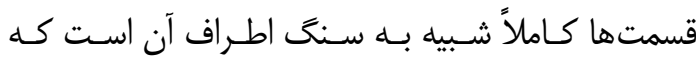

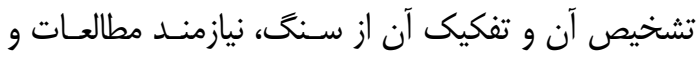

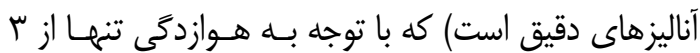
نمونه ملاط در بخش جله خانه اصلى جنوبى و يكى نمونه

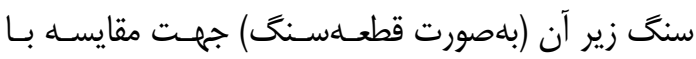

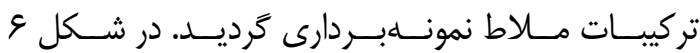
مستندنغارى محل بقاياى مشهود ملاط و آرايههاى ملاط ساخت در معبد ورجوى و همجنين محل نمونهبـردارىهـا مشخص كرديده است.

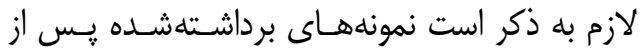

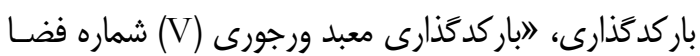

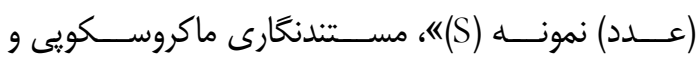

$$
\text { ميكروسكويى گرديد (شكل V). }
$$

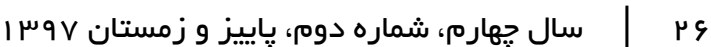




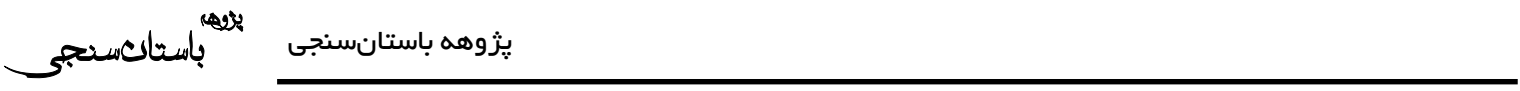
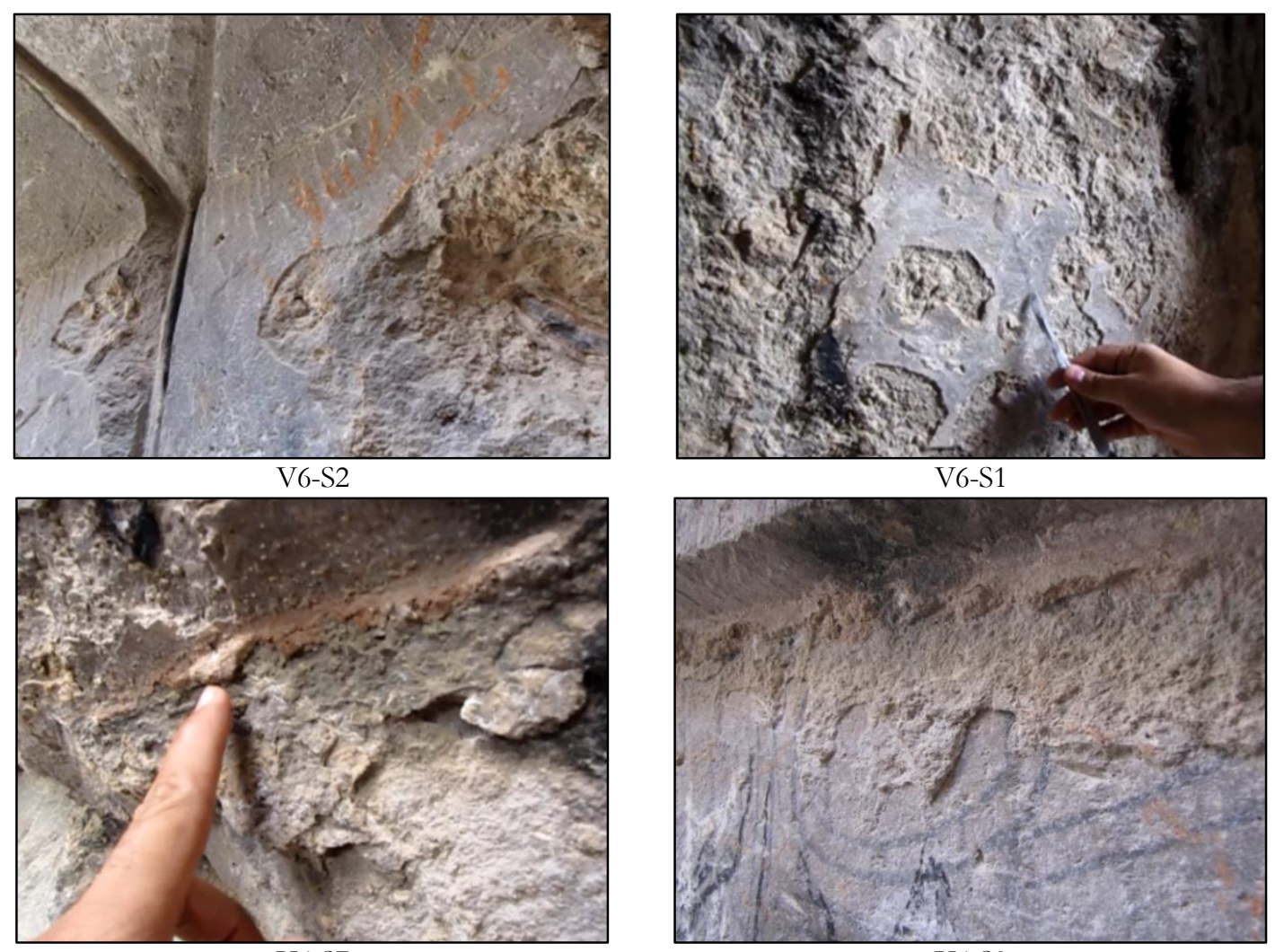

V6-S7

V6-S3

شكل V: تصاوير نمونهبردارى با توجه به فضاهاى كدكذارى شده در معبد ورجووى.

Fig. 7: Sampling images according to encoded spaces on the Verjuy Temple

V6 بلوسيله دستخاه ديفراكتومتر مـدل PW1800 سـاخت

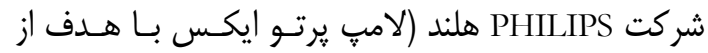

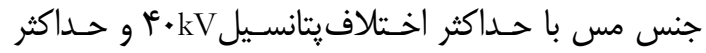

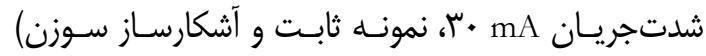

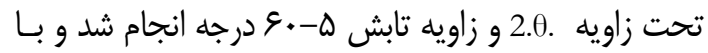
استفاده از نرمافزار Xpert high score plus انجـام كرفت

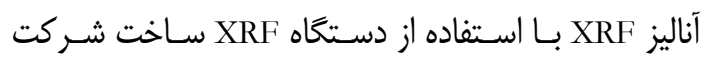
Philips

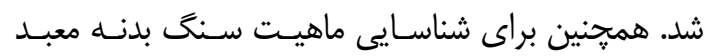

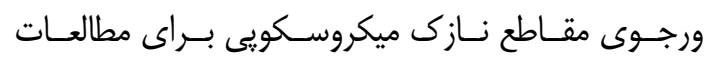

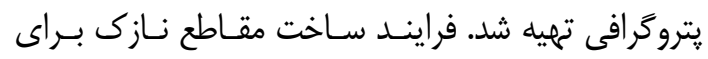
نمونdسنگ

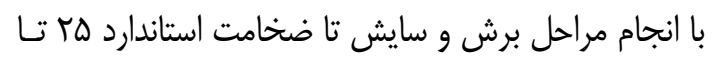

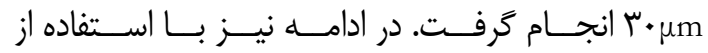

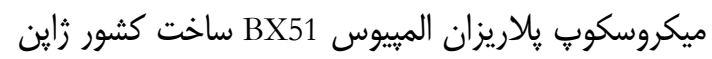

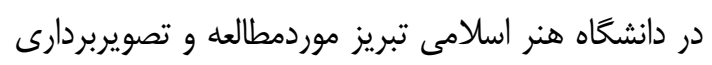
قرار گرفت.
روى بقاياى آن مانده است در زير اين لايه مـلاط ردى از

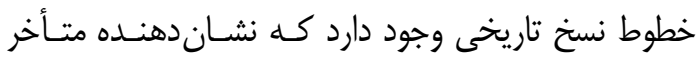
بودن اين ملاط است. نمونه قطعه سنگ بدنه داخلى فضاى V6 است كـه از ازاره بنا و در بخش زيرين ملاط ازاره قرار داشـته و بـهـواسـطه

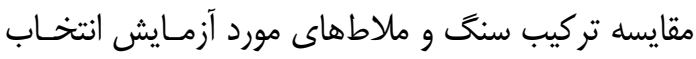

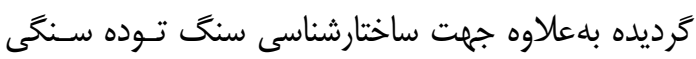

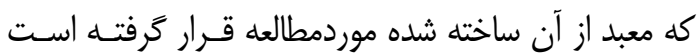

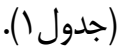

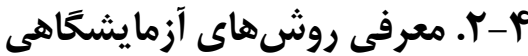

در اين تحقيق با هدف شناخت ساختار آرايهها و اندودهاى

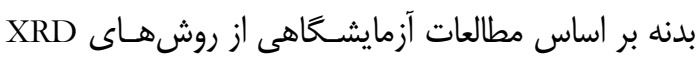
به روش و XRF استفاده شده است. در همين راستا جهت شناسـايى و تشــخيص فازهــاى كريســالى موجــود در

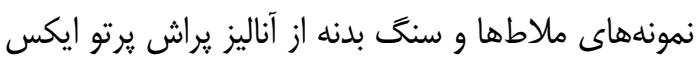
به روش يودرى بر ب نمونه ملاط از سطوح داخلى فضـاى

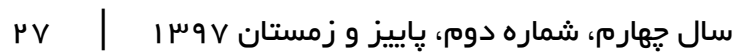


جدول (: مستندنغارى ماكروسكويى و ميكروسكويى نمونهاى موردمطالعه

Table 1: Macroscopic and Microscopic documentation of the Studied Samples

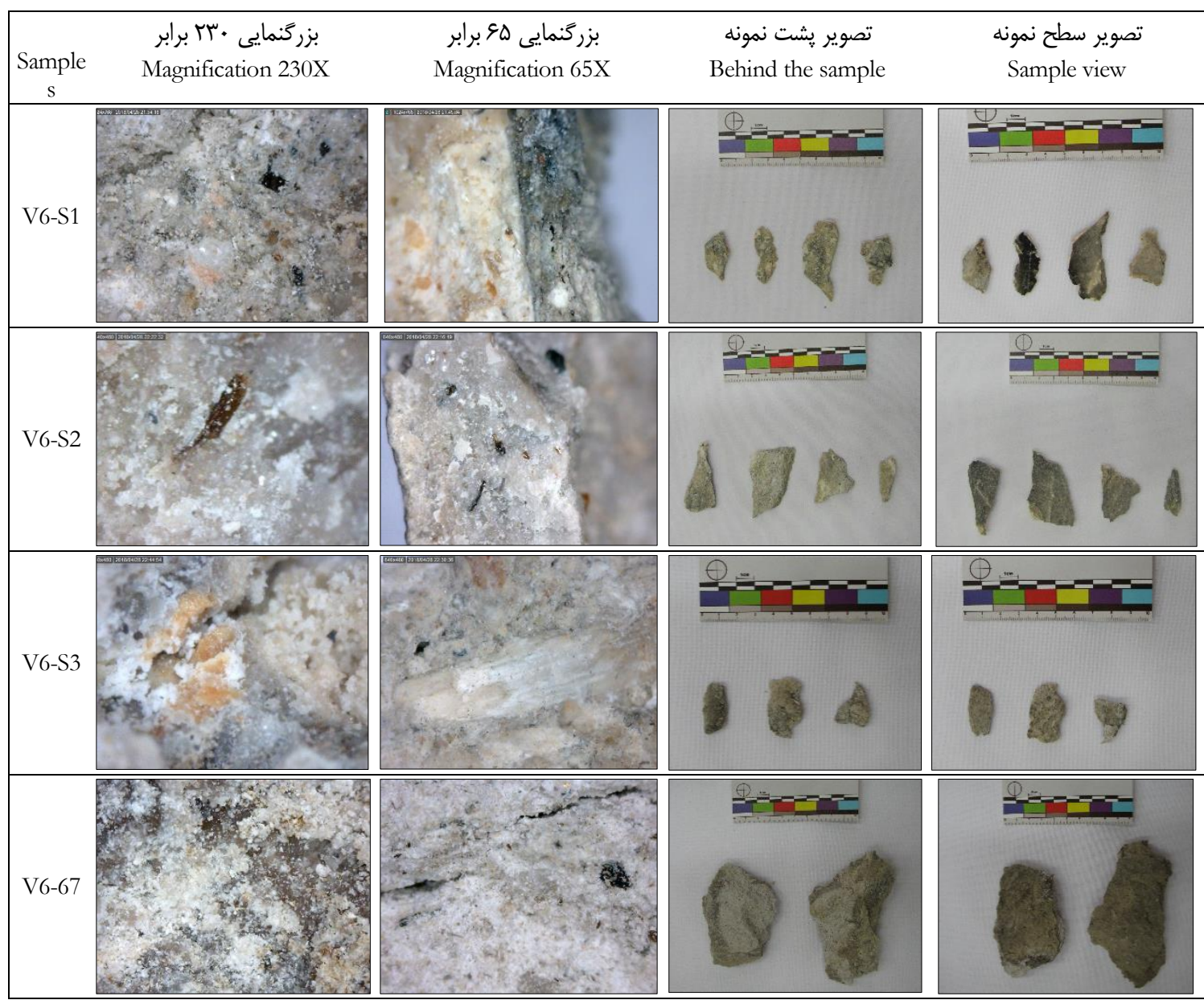

ه-r. آناليز يراش يرتوايكس

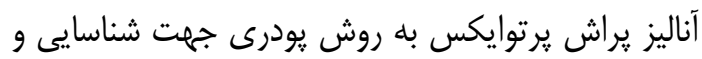

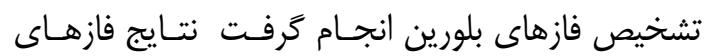

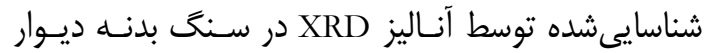

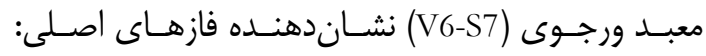

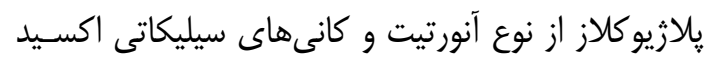

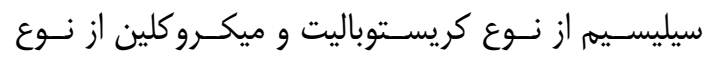

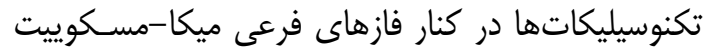

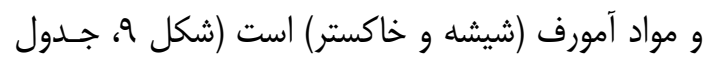

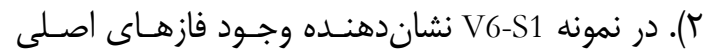

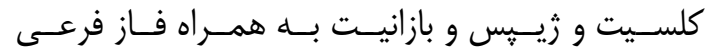

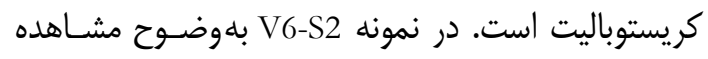

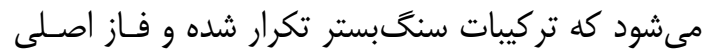
كلسيت و فازهاى فرعى زيبِ و بازانيت، كريسـتوباتيت،
ه. نتايج و يافتهها ه- (1. مطالعهُ مقطع نازك ميكروسكوبيى

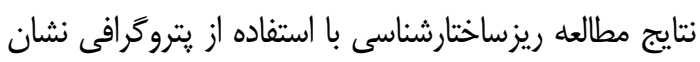

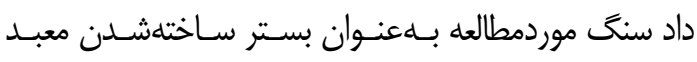

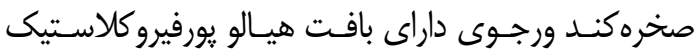

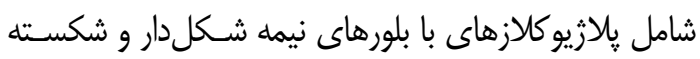

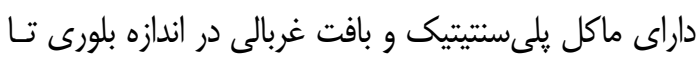

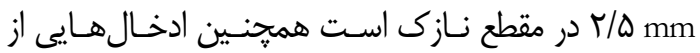

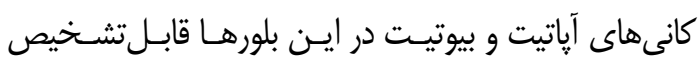

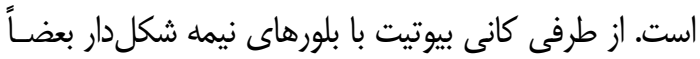

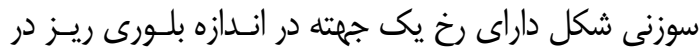

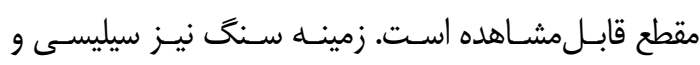

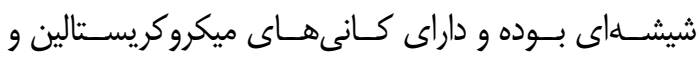
كرييتوكريستالين است (شكل^).

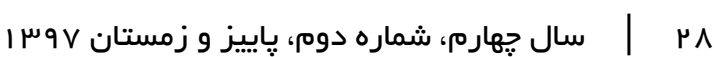




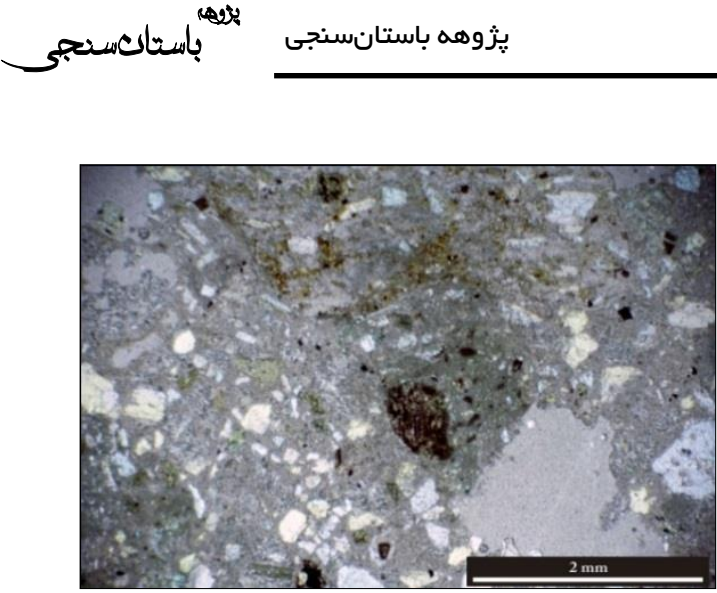

General view of Verjuy Tuff stone V6-S7-PPL+2.5X

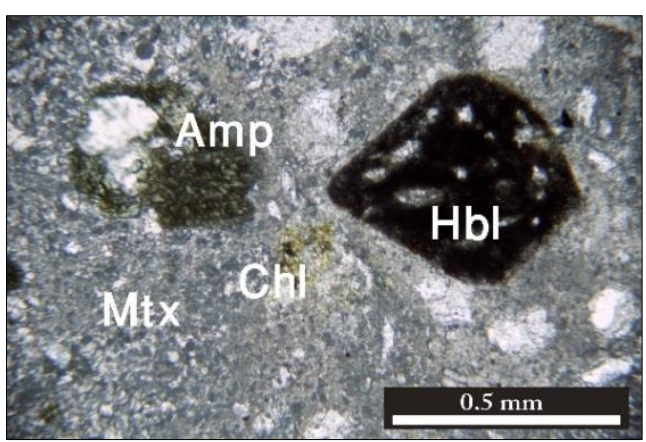

Hornblende(Hbl),Chlorite(Chl), Matrix(Mtx), Amphibolite (Amp); V6-S7-PPL+10X

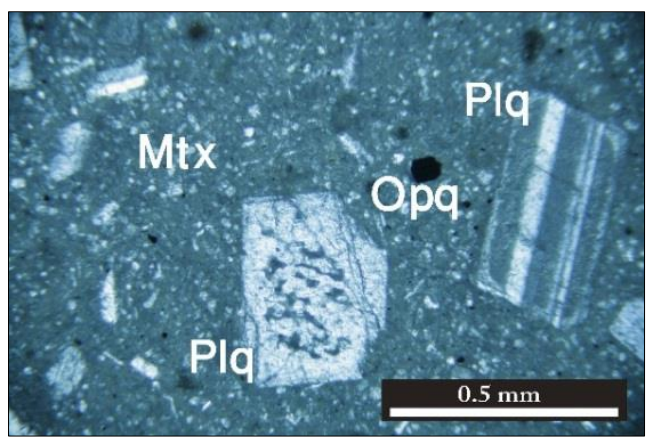

Plagioclase (Plq) with Sieve texture. V6-S7-XPL+2.5X

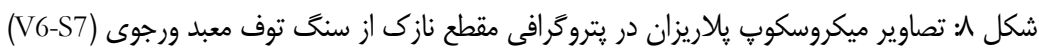

Fig. 8: Polarizing microscope image on the petrographic thin section of Tuff rock from Verjuy Temple (V6-S7)
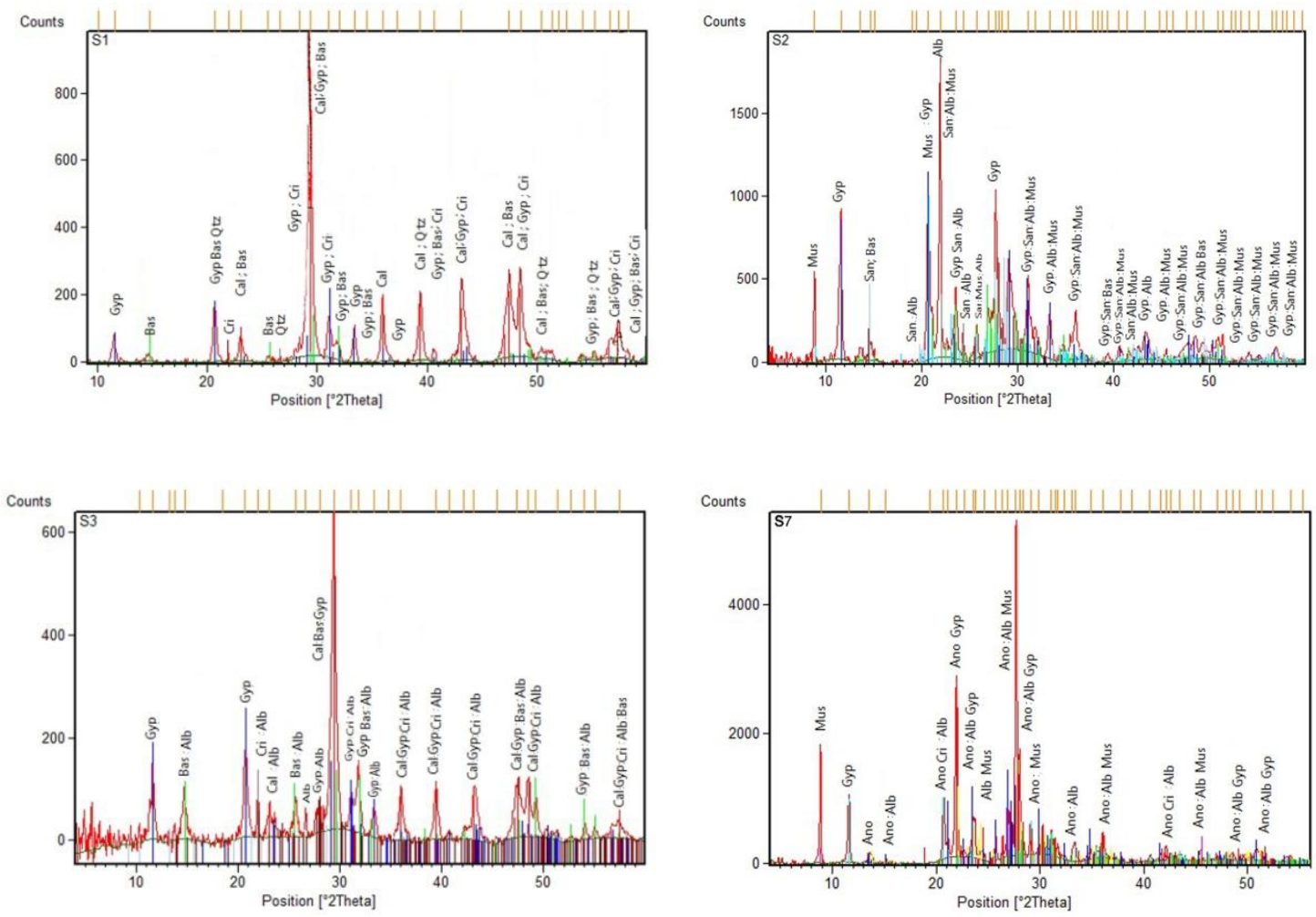

شكل ج: طيفهاى يراش يرتوايكس و فازهاى شناسايىشده كيفى از بدنه سنخى و ملاطهاى معبد ورجووى

Fig. 9: the X-ray diffraction spectra and qualitatively detected phases of rocky substrate and mortars of the Verjuy Temple

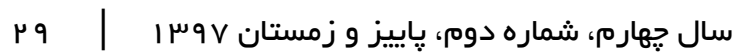


جدول r: نتايج فازشناسى كيفى با استفاده از يراش اشعه ايكس به روش يودرى از بدنه سنگى و ملاطهاى معبد ورجووى

Table 2: The Results of Qualitative Phase Studies Using XPRD from the rocky substrate and mortars of the Verjuy Temple

\begin{tabular}{|c|c|c|c|c|c|c|c|}
\hline $\mathrm{Sam}^{\text {Min }}$ & $\mathrm{Cal}$ & Gyp & Bas & Cri & $\mathrm{Plg}$ & Mic - Ill & Qtz \\
\hline V6-S1(Mor) & $\sqrt{ }$ & $\sqrt{ }$ & $\sqrt{ }$ & $\sqrt{ }$ & - & - & $\sqrt{ }$ \\
\hline V6-S2(Mor) & $\sqrt{ }$ & $\sqrt{ }$ & $\sqrt{ }$ & $\sqrt{ }$ & $\sqrt{ }$ & $\sqrt{ }$ & - \\
\hline V6-S3(Mor) & $\sqrt{ }$ & $\sqrt{ }$ & $\sqrt{ }$ & $\sqrt{ }$ & $\sqrt{ }$ & - & $\sqrt{ }$ \\
\hline V6-S7(Sto) & - & 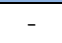 & - & $\sqrt{ }$ & $\sqrt{ }$ & $\sqrt{ }$ & - \\
\hline $\begin{array}{c}\text { Chemical } \\
\text { formula \& } \\
\text { Ref Number }\end{array}$ & \multicolumn{7}{|c|}{ 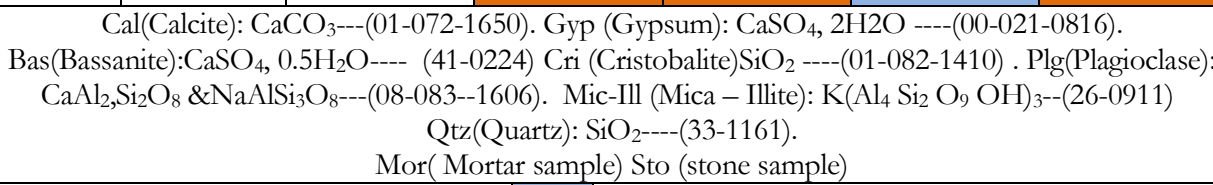 } \\
\hline \multicolumn{4}{|c|}{ Major Phase(s) } & \multicolumn{4}{|c|}{ Minor Phase(s) } \\
\hline
\end{tabular}

است كه توفهاى آتشفشانى در طول تاريخ بشر بهواسطه

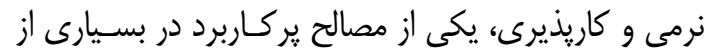

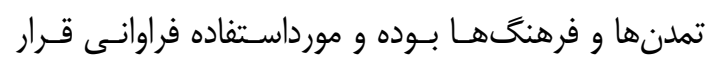

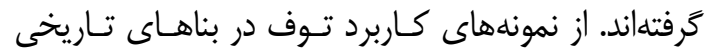

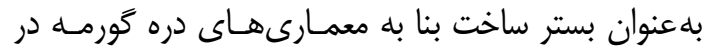

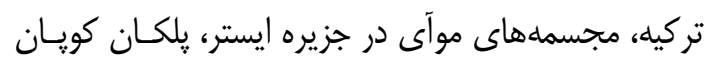

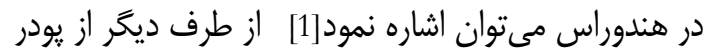

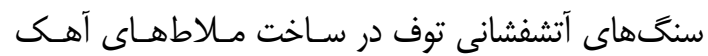

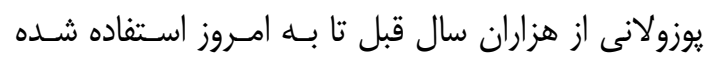

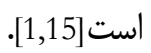
آن گونه كه از نتايج دادههاى آناليزى برمى آيد ملاط

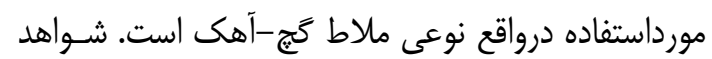

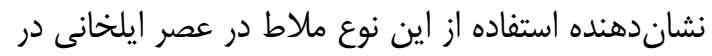

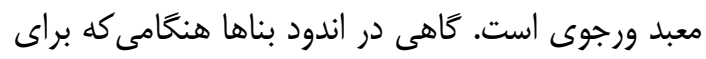

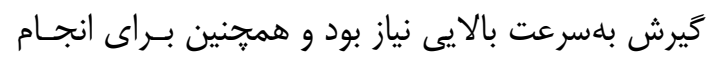

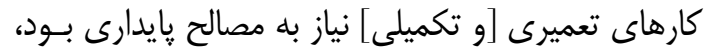
از تر كيب كَ و آهك استفاده مى كردهاند. بلدواقع استفاده از جنين تركيبى برخى مزايا را داراست
يازيوكلاز ميكرو كلين فازهاى فرعى ميكـا -مسـكوييت

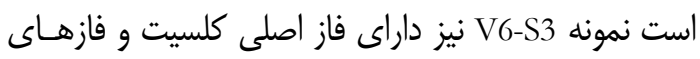
فرعى زييس و بازانيت، كريستوباليت، يلازيوكلاز است.

\section{ه-"r. نتايج آناليز فلورسانس ير توايكس}

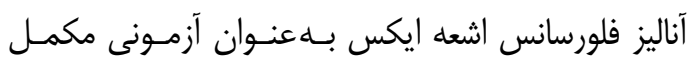

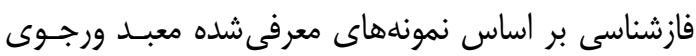

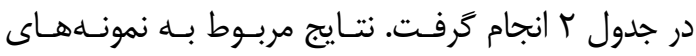
يودرى بهصورت اكسيدهاى اصلى (جدول ب) ارائه كرديده است. كه در نمونه V6-S2 و V6-S7 ميزان بـالاى اكسيد إنسيد

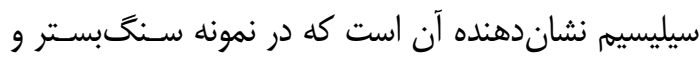

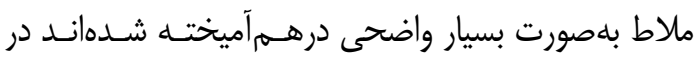
نمونه شماره V6-S1 و V6-S3 بلوضوح تركيـب مشـابه از داز عناصر قابل استباط است.

\section{و. بحث در نتايج و يافتهها}

معبد ورجوى مراغه و فضاهاى كندهشدُ اطـراف آن از دل

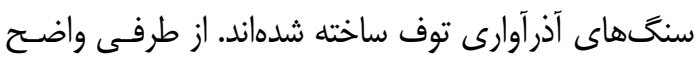

جلول سا: عناصر اصلى (اكسيد) ملاطها و نمونه سنگ معبد ورجوى با استفاده از تجزيه شيميايى به روش WRF) XRF) Table 3: Main elements (oxides) of mortars and samples of the rocky substrate of the Temple of Verjuy using chemical analysis by XRF method (W\%)

\begin{tabular}{|c|c|c|c|c|c|c|c|c|c|c|c|}
\hline Sam & $\mathrm{SiO}_{2}$ & $\mathrm{Al}_{2} \mathrm{O}_{3}$ & $\mathrm{Fe}_{2} \mathrm{O}_{3}$ & $\mathrm{CaO}$ & $\mathrm{K}_{2} \mathrm{O}$ & $\mathrm{MgO}$ & $\mathrm{TiO}_{2}$ & $\mathrm{MnO}$ & $\mathrm{P}_{2} \mathrm{O}_{5}$ & $\mathrm{SO}_{3}$ & L.o.I \\
\hline V6-S1 & 6.51 & 1.05 & 0.51 & 39.67 & 0.21 & 0.81 & 0.027 & 0.001 & 0.097 & 17.44 & 31.01 \\
\hline V6-S2 & 37.46 & 6.32 & 1.13 & 14.14 & 2.10 & 0.57 & 0.138 & 0.001 & 0.089 & 16.45 & 21.32 \\
\hline V6-S3 & 17.87 & 1.81 & 0.68 & 31.80 & 0.60 & 0.72 & 0.046 & 0.001 & 0.146 & 21.56 & 24.21 \\
\hline V6-S7 & 58.64 & 9.06 & 2.09 & 7.46 & 3.29 & 0.91 & 0.240 & 0.014 & 0.118 & 6.19 & 11.13 \\
\hline
\end{tabular}


در آرائُ مقرنس و سنگَبستر آن است (شكل •(1) كه ايـن

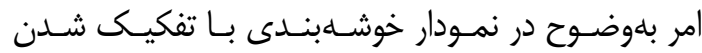

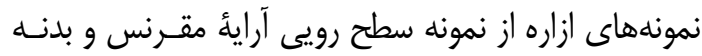

سنكى نشان داده شده است (شكل (I-r (ا).

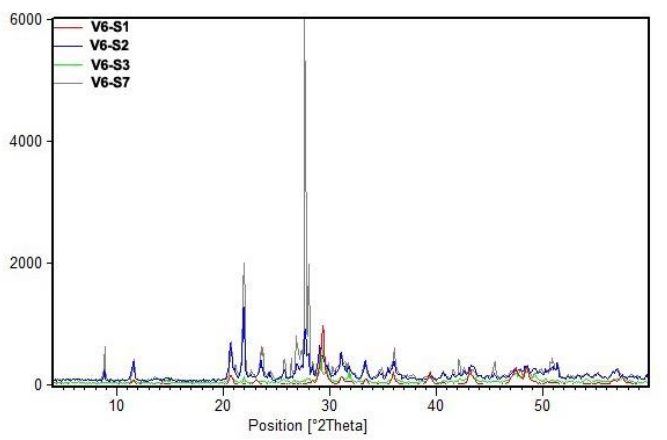

شكل • (: مقايسه طيفهاى ثراش برتوايكس نمونههاى مورد

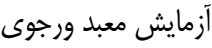

Fig. 10: Comparison of $\mathrm{x}$-ray diffraction spectra of the studied samples from Vorjoy Temple

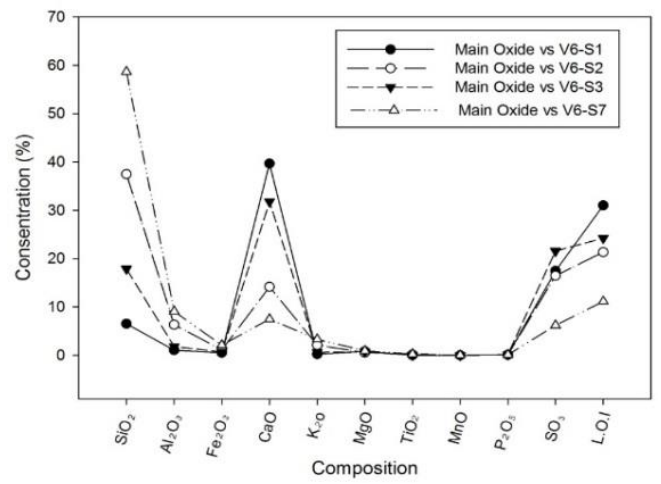

شكل ||(: نمودار مقايسه اكسيدهاى اصلى نمونههاى موردمطالعه با

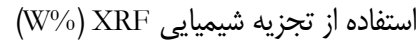

Fig. 11: Comparison of the main oxides of the studied samples using XRF chemical analysis (W\%)

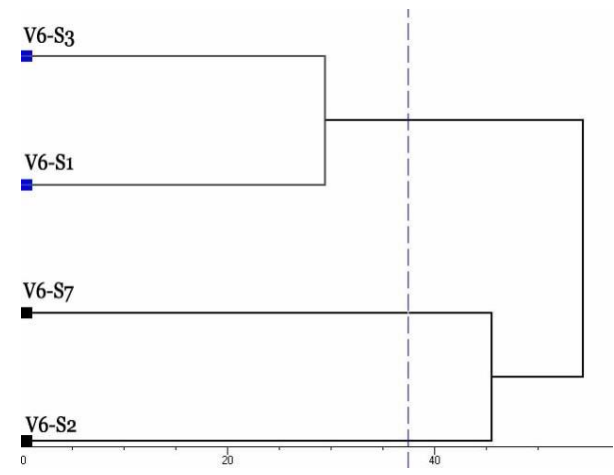

شكل r (: نمودار خوشهبندى طيفهاى يراش يرتوايكس نمونههاى

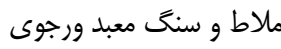

Fig. 12: Cluster diagram of XRD spectra. Mortar and Rock samples of Verjuy temple

$\mu$

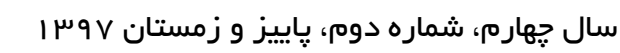

بلنحوى كه كج باعث عمل آورى سريع مى شود و از طرفى

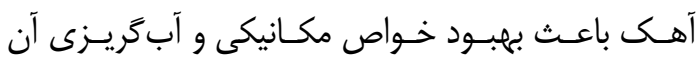

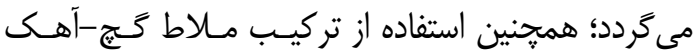

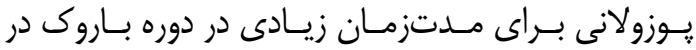
نماهاى روم استفاده شده است[15].

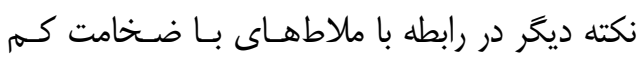

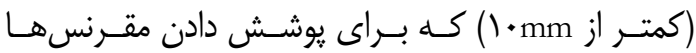

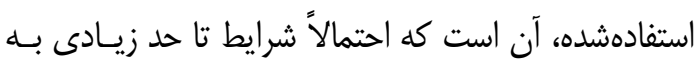

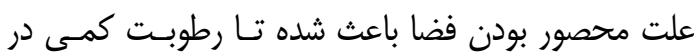

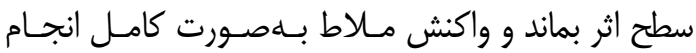

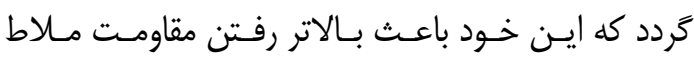

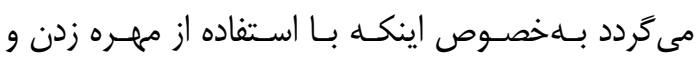
صيقل كارى ملاط، ميزان تخلخل آن به به حـداقل رسـيده و اين امر نيز باعث استحكام بيشتر آن گرديده است.

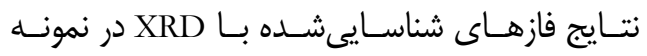

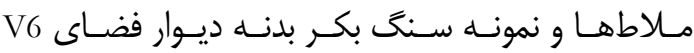
نشان دهنده فازهاى اصلى و فازهاى فرعى هستند. تفـاوت

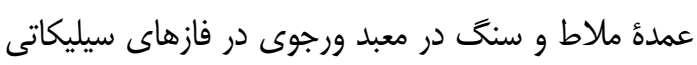

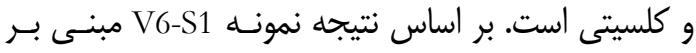

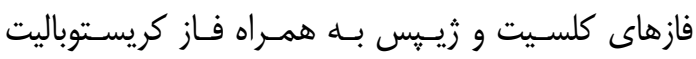

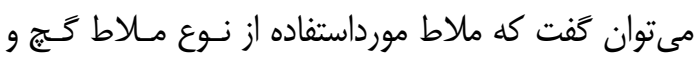

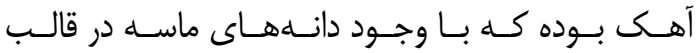

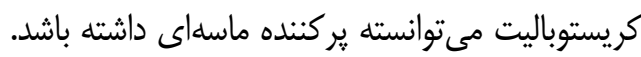

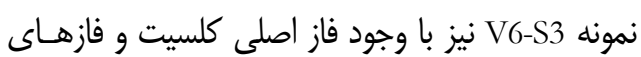

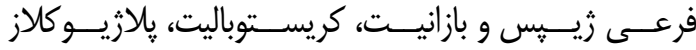

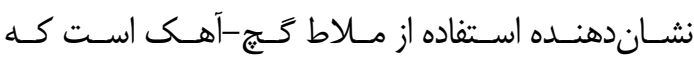

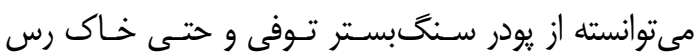

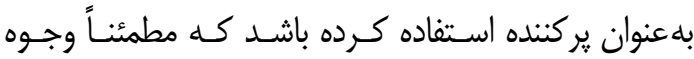

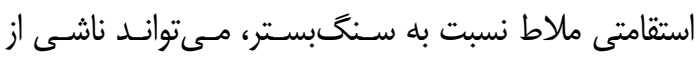

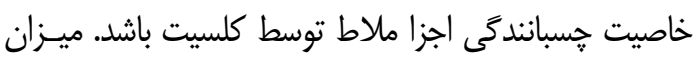

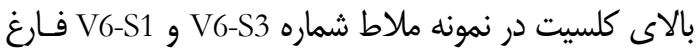
از بست آهكى مىتواند ناشى از محتواى كلسـيتى خاكسـتر

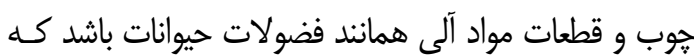
ذرات آن در نمونه ملاطها بلوضوات ماد الماند فضولات حيده مى شود.

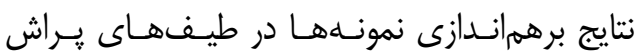

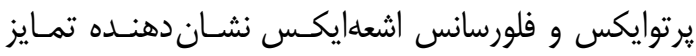
مشخص و دقيق دو نمونه ملاط ازاره از ملاط استفادهشده 
معبد ورجووى، از ملاط بلعنوان اندود استفاده شـــه اسـت

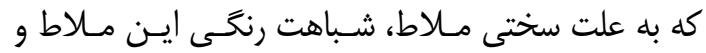

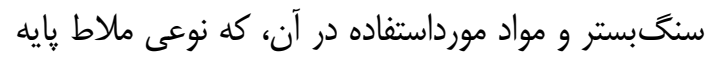

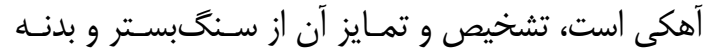

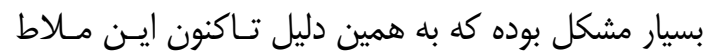

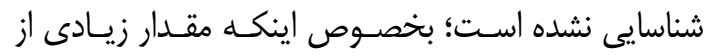

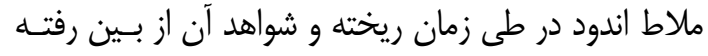

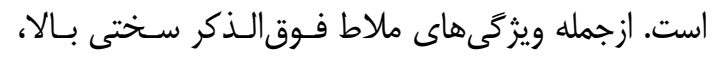

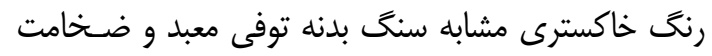

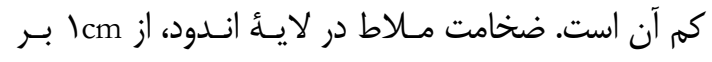

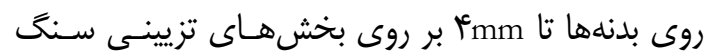

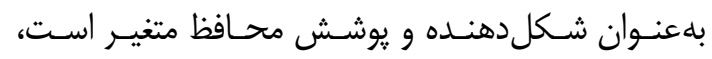

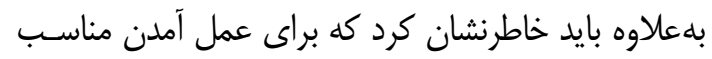

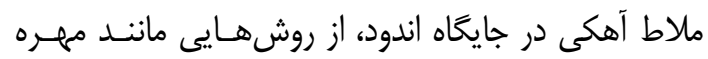

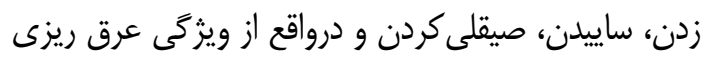
ملاط استفاده كردهاند.

\section{سياسگز ارى}

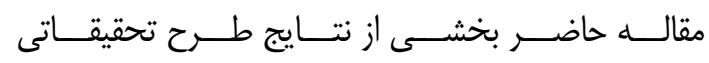

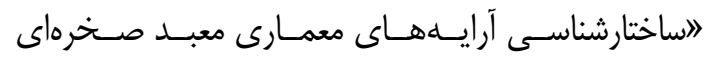

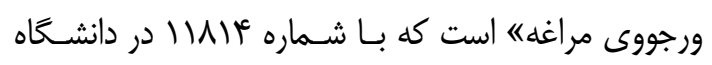

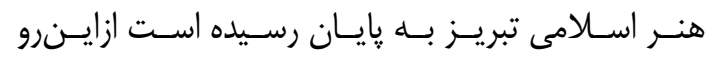

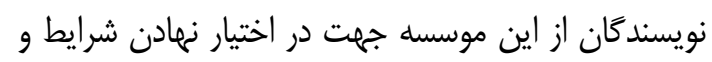

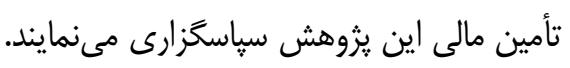

\section{References}

[1] Razani M, Baghbanan A., Emami SM., Delgado Rodriguez J. Optimization of Traditional Lime-based Mortars for Cement Replacement Toward Consistent Conservation of Rocky Architecture of the Kandovan Historical Village. J Reasearch Archaeom 2018;37:125-38. [in Persian]

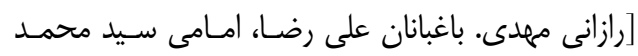

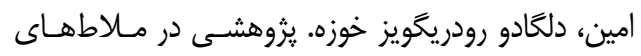

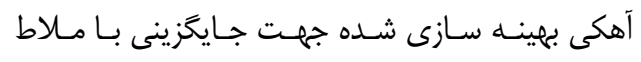

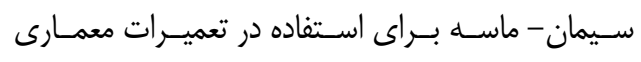

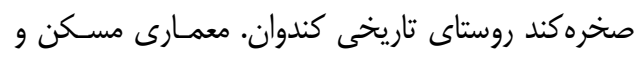

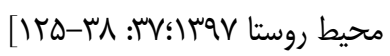

[2] Amini BF, Razani M, Asghari KE, Emami

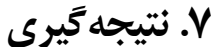

روستاى ورجووى و بخصوص بخش قديمى آن كه معبـــ

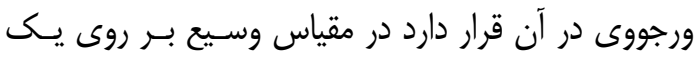

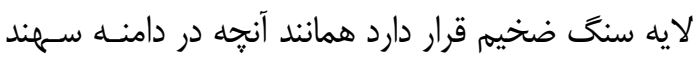

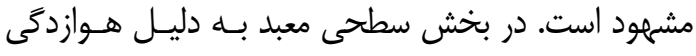

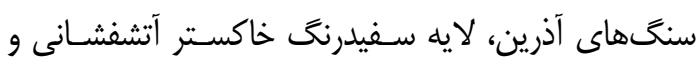

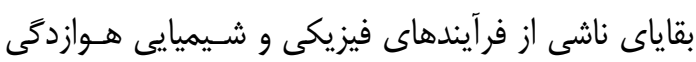

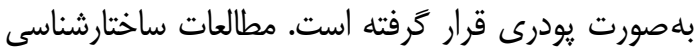

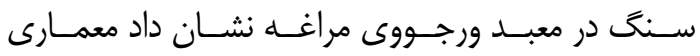

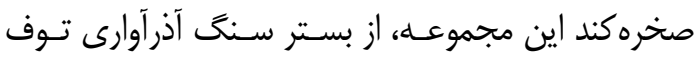

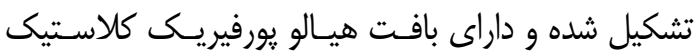
شامل فنوكريستهاى يلازيو كلاز نيمه شكلدار و و شكسته

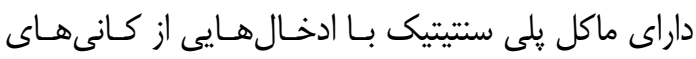

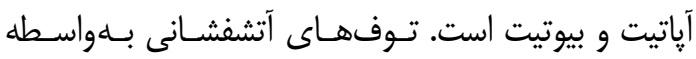

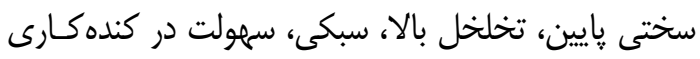

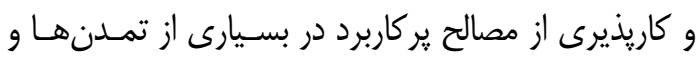

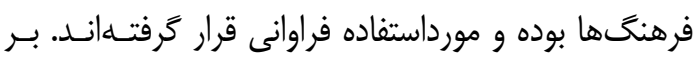

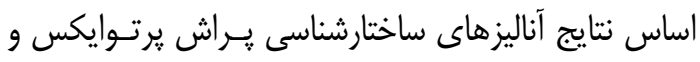

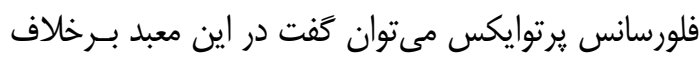

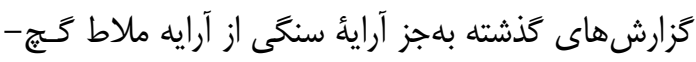

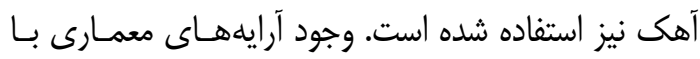

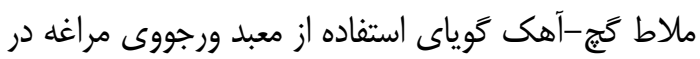

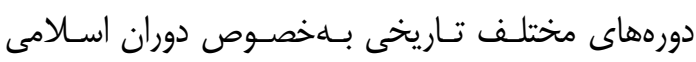

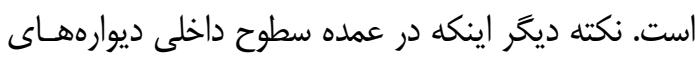

SMA. Characterization and Pathology of Pyroclastic Stones in the Cut Rock Historical Architecture of Kandovan Village 2015;1:1-16. [in Persian] doi: https://doi.org/10.29252/jra.1.1.1

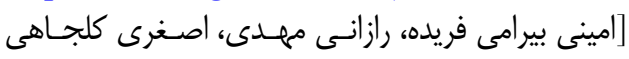

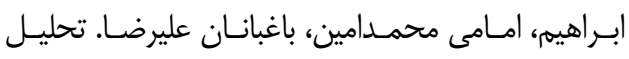

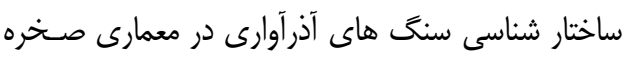

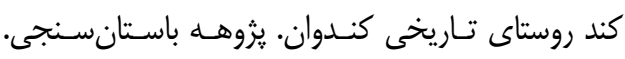

[.19-1:1 (1)

[3] Varjavand P. Temple of Mehri or Imamzadeh Masoom Vargovi. Hist Surv 1972;7:89-100. [in Persian]

[ورجاوند يرويـز. نيايشـاه مهـرى يـا امـامز اده معصـوم

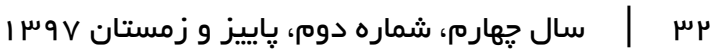




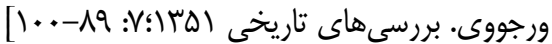

[4] Muhammad ben hoqoul. Picture of the earth. In: Shahar $\mathrm{T}$ by J, editor., Tehran: Iran Culture institute; 1966. [in Persian] [محمد بن حوقل. صـوره الارض. ترجمــُ شـعار جعفـر.

تهران: بنياد فرهنگ ايران؛ هعسا.]

[5] Moghadasi A. The best division in the definition of the denominator. Translated, Tehran: moalefan and motarjeman Co; 1982. [in Persian]

[مقدسى ابوعبداله محمد. احسـن التقاسـيم فـى معرفـــ

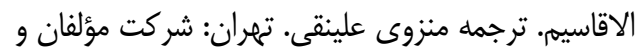

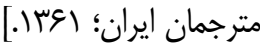

[6] Al-Hamawi Y. Mu jam al-buldan. In: Wustenfeld F, Monzavi T by: A, editors., Tehran: ICHN; 1866. [in Persian] ]حموى ياقوت. معجم البلدان. ترجمـهـ منـزوى علينقـى.

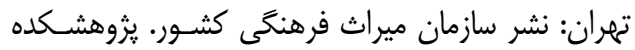

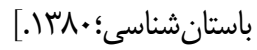

[7] Naseri Som'eh H, Firouzmandi B, Sa'dati M. Archaeological Investigation of Göyce Qala: An Urartuian Castle in Maragheh Plain, Northwestern Iran. Archaeol Stud 2015;7:147-65.

doi: https://doi.org/10.22059/JARCS.2015.56 685 [in Persian]

[ناصرى صـومعه حسـين، فيروزمنـدى بهمـن، سـعادتى

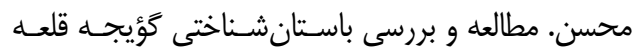

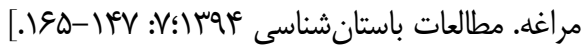

[8] Pazouki N, Shadmehr A. Recorded works by Iran in the national monuments from 1931 to 2005. Tehran: Cultural Heritage and Tourism Organization of Iran; 2005. [in Persian]

] يازوكى ناصر، شادمهر عبدالكريم. آثار ثبتشدهى ايـران

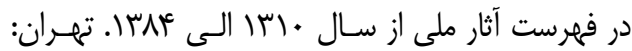

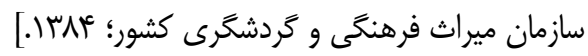

[9] Deghati Najd M. A brief study about Mehr temple in Maraghe. Manzar 2011;3:60-3. [in Persian]

$$
\begin{aligned}
& \text { [دقتى نجد ميثم. شاهد مهر؛ بازشناسى معبد مهر مراغـه. }
\end{aligned}
$$

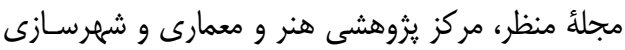

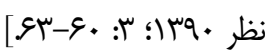

[10] Akasoy A, Burnett CSF, Yoeli-Tlalim R. Islam and Tibet: interactions along the musk routes. Ashgate Publishing, Ltd.; 2011.

[11] Azad M, Ansari M. Ancient Iranian Religious Buildings (pre-Islamic). Proc. First Natl. Conf. Iran. Stud. Arts Archeol., Tehran: Iran Science institute; 2004, p. 138. [in Persian]

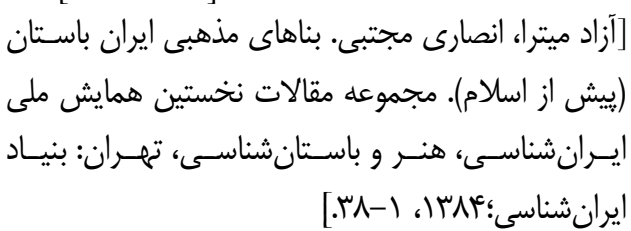

[12] Bigbabapor Y, Gholamieh M. History of Photography in Maragheh. Qom: Majmae Zajhaer Islami; 2011. [in Persian]

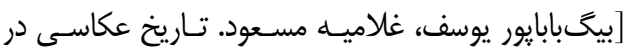

مراغه. قم: مجمع ذخاير اسلامى؛. وسו.].

[13] Bigbabapor Y. Maragheh shrines, scriptures and documents. Qom: Majmae Zajhaer Islami; 2009. [in Persian]

]بيخبابايور يوسف. مزارات، سنگ نوشتها و اسناد مراغه.

قم: مجمع ذخاير اسلامى؛ MM Mسا.]

[14] Razani M, Conejero FM, Mansouri IM, Afsharinezhad H. Preparation of Thin Sections of Porous Materials for Polarizing Microscope Investigation in Archaeometry. J Reasearch Archaeom 2017;3:45-60. doi: https://doi.org/ 10.29252/jra.3.2.45 [in Persian]

[رازانى مهلدى، مارتينز گَونيخرو فلى، منصورى اصـفهانى

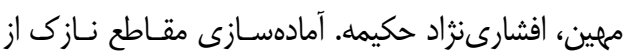

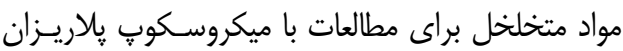

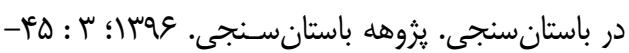

$[\mathcal{F}$.

[15] Torraca G. Lectures on materials science for architectural conservation 2009. 